\title{
Phytochemical-Based Nanomedicine for Advanced Cancer Theranostics: Perspectives on Clinical Trials to Clinical Use
}

This article was published in the following Dove Press journal: International Journal of Nanomedicine

\author{
Madhusmita Dhupal $\mathbb{1}^{\prime}$ \\ Devasish Chowdhury $\mathbb{D}^{2}$ \\ 'Department of Microbiology, Wonju \\ College of Medicine, Yonsei University, \\ Wonju 26426, Republic of Korea; \\ ${ }^{2}$ Material Nanochemistry Laboratory, \\ Physical Sciences Division, Institute of \\ Advanced Study in Science and \\ Technology, Guwahati 781035, India
}

\begin{abstract}
In the current chapter, a new strategic compilation of phytochemicals with potent antitumor properties has been addressed, most importantly focusing on cell cycle arrest and apoptotic signaling mechanism. A promising approach in tumor prevention is to eliminate cancer cells preferably via cell cycle arrest and programmed cell death with lesser harm to neighboring normal cells. Cancer cells have a survival advantage to escape apoptosis and relentlessly divide to proliferate, gearing up the cell cycle process. Recently, the use of phytochemical-derived conjugated chemotherapeutic agents has increased dramatically owing to its biocompatibility, low cytotoxicity, low resistance, and dynamic physiochemical properties discriminating normal cells in the treatment of various cancer types. For decades, biomedical investigations have targeted cell cycle and apoptotic cell death mechanism as an effective cancer-killing tool for systemically assessing the potential biological interactions of functional phytocompounds compared to its synthetic counterparts during their complete life cycles from entry, biodistribution, cellular/molecular interactions to excretion. Newly emerging nanotechnology application in anticancer drug formulations has revolutionized cancer therapy. Tissue-specific phyto-nanomedicine plays a vital role in advanced cancer diagnostics using liposome, micelle, and nanoparticles as a precise and effective delivery vehicle. This chapter specifically focuses on the therapeutic phytomolecules approved by the Food and Drug Administration (FDA, USA) along with phyto-chemopreventives currently on clinical trials (Phase-I/II/III/IV). Besides, detailed coverage is given to the FDA-approved nanotechnology-based formulations only in the areas of cancer theranostics via cell cycle arrest and apoptotic pathways including present challenges and future perspectives.
\end{abstract}

Keywords: phytochemicals, cancer therapeutics, apoptosis, cell cycle arrest, chemopreventive agents, clinical trials

\section{Introduction}

Phytochemicals have been gaining increasing attention as a promising anticancer agent, with less systemic toxicity in special relation to the regulation of cell cycle, inducing apoptosis of cancer cells, for the past few decades. Cancer has emerged as a global threat to public health along with the second major reason for death worldwide. Cancer is also called as malignancy, a population of erratically growing abnormal cells which can metastasis to other tissue organs of the body. ${ }^{1}$ The International Agency for Research on Cancer (IARC) has released 'GLOBOCAN $2018^{\prime}$ the latest global cancer burden database. According to IARC, new cancer cases rises to 18.1 million in 2018 and mortality reached 9.6 million projecting a rise of 
cancer prevalence to 23.6 million by 2030 around the world. $^{2}$ There are more than 100 types of cancer have been detected so far. Among all, lung, colorectal, stomach, liver, and breast cancers are the most prevalent and the foremost cause of cancer death among all cancer types, worldwide. To combat these, phytocompounds and their derivatives are either used alone, in combination with anticancer drugs or as nanomedicine formulations for better cancer theranostics over the conventional approach. Currently, plant products chiefly secondary metabolites such as phenols, alkaloids, flavonoids, flavonols, terpenoids, terpenes, steroids, etc., are among the leading source of anticancer compounds under clinical trials and clinical use. $^{3}$

Apoptosis is a distinctive form of programmed cell death, a steadily regulated process, which has received remarkable attention in the field of cancer research. Apoptosis progresses through extracellular death receptor pathways as well as intracellular mitochondrial signaling pathways activating various Caspase cascades leading to cell cycle arrest and cell death. ${ }^{4}$ Cell growth and proliferation proceed through different phases of the cell cycle such as growth phases (G1/G2), S-phase (DNA synthesis), and M-phase (mitosis). ${ }^{5}$ Also, the initial G0-phase (quiescent state) awaiting the favorable time to enter the G1 phase. Cell cycle phases are regulated by binary enzyme cyclindependent kinases (catalytic CDKs) in interaction with regulatory cyclin subunits and further, $\mathrm{CDKs}$ are controlled by enzyme cyclin-dependent kinase inhibitors (CDKIs). Therefore, cancer initiation, promotion and progression can be blocked by inducing cell cycle arrest at $\mathrm{G} 1 / \mathrm{S}, \mathrm{S} / \mathrm{G} 2$, and $\mathrm{G} 2 / \mathrm{M}$ phase transition, triggering the apoptotic cell death mechanism by inactivating complex CDKs/cyclin phosphorylation. ${ }^{5}$ In this chapter, we have focused on two categories of phytochemicals for cancer treatment: I. DNA damage and cell cycle arrest inducing phytochemicals and II. Apoptotic phytobioactives. For example, phenyl ethyl ester, luteolin, kaempferol, vincristine, butyrate (nab), sulforaphane, lycopene, curcumin, genistein etc., induce DNA damage and cell cycle arrest at $\mathrm{G} 0 / \mathrm{G} 1, \mathrm{G} 2 / \mathrm{M}$ and $\mathrm{G} 2 / \mathrm{S}$ phase arrest in cancer cells. Apoptosis promoting phytomolecules discussed here are irinotecan, acetoxycharvicol acetate, quercetin, piperine, curcumin, capsaicin, sanguinarine etc.

Nanotechnology is rapidly gaining global attention as an integral part of biomedical research specifically focusing on cancer diagnosis. The unique properties of nanophytomedicine are their nano-size, high surface area to volume ratio, optical activity, surface reactivity, which enables these adsorb efficiently with phytocompounds, and chemotherapeutics for active or passive tissue-specific drug delivery. Moreover, these nanoformulations reduce systemic toxicity enhancing bioavailability with controlled and sustained release to the target site. Efficient nanocarriers used globally are liposomes, polymeric nanoparticles, polymeric micelles and nanodispersion among others. ${ }^{6}$ Nano-phytomedicines such as doxorubicin hydrochloride liposome, vincristine sulfate liposome, irinotecan hydrochloride liposome, paclitaxel albumin-stabilized nanoparticle formulation, paclitaxel injection concentrate for nanodispersion, docetaxel nanoparticles are amongst the FDA-approved nanoformulations for cancer therapeutics, currently in clinical use. ${ }^{6}$

The present chapter provides detailed knowledge of the cancer therapeutic phytomolecules approved by the Food and Drug Administration (FDA, USA) inclusive of phytobioactives currently on the clinical trials (Phase-I/II/III/ IV). Besides, detailed coverage is given to the newly emerging nanotechnology-based formulations (FDAapproved) in the areas of cancer theranostics via cell cycle arrest and apoptotic pathways including present challenges and future perspectives. Finally, this chapter can provide updated knowledge of anticancer medicinal plants to the pharmaceutical companies, clinicians and researchers to explore and treat malignant tumors.

\section{Current Status of Cancer Burden Worldwide}

New cancer cases rise to 18.1 million in 2018 and mortality reached 9.6million projecting rise of cancer prevalence to 23.6 million by 2030. The International Agency for Research on Cancer (IARC) has released 'GLOBOCAN 2018' the latest global cancer burden database, which provides an estimated number of new cases diagnosed (incidents) and death (mortalities) comprising a survey of 185 countries inclusive of 36 cancer types of all sexes and all age groups combined. ${ }^{2}$

\section{Global Cancer Burden by Population}

Overall worldwide cancer patterns depict that for both sexes combined including all age groups, about $48.4 \%$ of the new cases diagnosed and more than $57.3 \%$ of the cancer mortalities occurred in Asia alone, in 2018 (Table 1). In contrast, the given data show that Africa 
Table I Global Cancer Burden in 2018

\begin{tabular}{|l|l|l|l|l|}
\hline Population & $\begin{array}{l}\text { Estimated Number of New Cases in } \\
\mathbf{2 0 1 8}\end{array}$ & $\begin{array}{l}\text { \% of } \\
\text { Incidents }\end{array}$ & $\begin{array}{l}\text { Estimated Number of Mortalities in } \\
\mathbf{2 0 1 8}\end{array}$ & $\begin{array}{l}\text { \% of } \\
\text { Mortalities }\end{array}$ \\
\hline Asia & $8,750,932$ & $48.4 \%$ & $5,477,064$ & $57.3 \%$ \\
Africa & $1,055,172$ & $5.8 \%$ & $6,93,487$ & $7.3 \%$ \\
America & $3,791,517$ & $21.0 \%$ & $1,371,024$ & $20.3 \%$ \\
Europe & $4,229,662$ & $23.4 \%$ & $1,943,478$ & $14.6 \%$ \\
Oceania & $2,51,674$ & $1.4 \%$ & 69,974 & $0.73 \%$ \\
\hline
\end{tabular}

Note: Estimated numbers of incidents and mortalities include both sexes and all cancer types combining all age groups worldwide.

documented with the least number of new cancer cases $(5.8 \%)$ as well as the least number of mortalities (7.3\%) among all populations globally. The Americas (North America, Latin America, and the Caribbean) estimated to have $21.0 \%$ of new cancer cases and $20.3 \%$ of cancer death worldwide. Although Europe has less of the total world population, it accounts for high $(23.4 \%$ of incidents and $20.3 \%$ of mortalities) cancer rates. Top ten countries with the highest cancer rate including both males and females come from Europe, Oceania, and America. In contrast to other populations of the world, Oceania has the least $1.4 \%$ of cancer incident cases with fewer portions $(0.73 \%)$ of cancer deaths. Asia has the highest incidents of cancer along with mortalities as it comprises of the largest population $(59.76 \%)$ of the world. To further worsen the scenario, most countries suffer from poor prognosis, inadequate facilities for early diagnosis, and timely treatment to counter cancer prevalence. ${ }^{2}$

\section{Global Cancer Burden by Type and Sex}

Lung, colorectal, stomach, liver, and breast are the most frequent sites of cancer occurrence which is the foremost cause of cancer death worldwide (Figure 1). Globally, there were 2.09 million (11.6\%) new cases and 1.76 million (18.4\%) lung cancer deaths estimated in 2018, out of which $60.7 \%$ cancer deaths occur in Asia alone, making lungs as the topmost cancer site among all cancer types. Breast cancer is the second most diagnosed cancer (11.6\%), followed by colorectal cancer (10.2\%), prostate cancer $(7.1 \%)$, and fifth place accounts for stomach cancer (5.7\%). After lung cancer and breast cancer, colorectal cancer is the third leading cause of cancer death (9.2\%), fourth stomach cancer $(8.2 \%)$, and fifth liver cancer $(8.2 \%)$ including both sexes and all age group. In terms of mortality by sex, breast cancer is the foremost and leading $(24.2 \%)$ cause of cancer death among women, followed by colorectal cancer (9.5\%), lung cancer (8.4\%), and fourth leading cervical cancer (6.6\%). Male $(68 \%)$ are more vulnerable to lung cancer death than females (33\%), followed by liver cancer $(10.2 \%)$ and stomach cancer (9.5\%). Colorectal cancer (9\%) and prostate cancer (6.4\%) ranked fourth and fifth leading cause of cancer death in men. ${ }^{2}$

\section{Existing Challenges in Cancer Therapeutics}

Existing anticancer drugs possess severe side effects including severe damage to the surrounding normal cells, anemia due to bone marrow suppression, diarrhea/constipation, digestive tract infection, inflammation, immunosuppression, and multiorgan toxicity. The challenging feature of the cancer cell is frequent mutations and nonresponsive to the prescribed drugs. ${ }^{3}$ Therefore, given the challenging circumstances of present chemotherapy, plantbased newer anticancer drugs using green and eco-friendly process is strongly demanded.

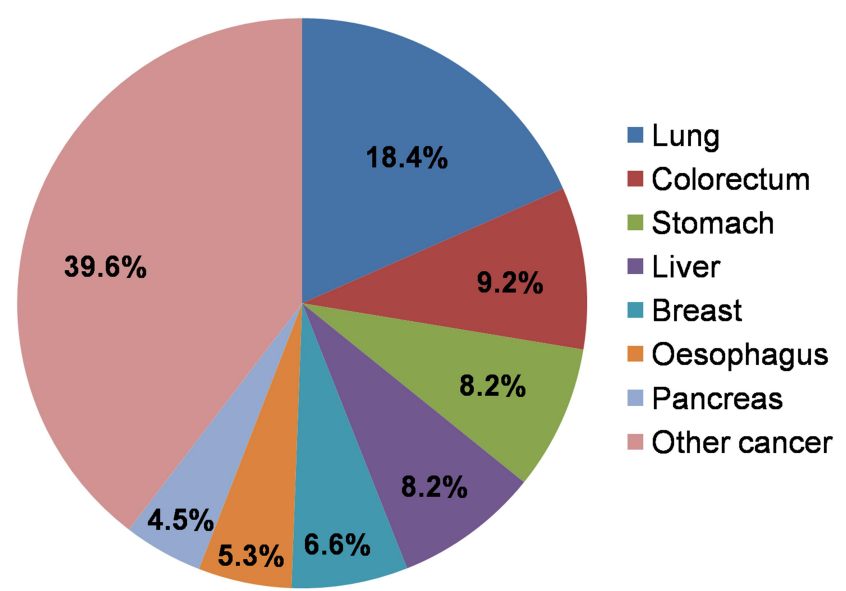

Global Cancer Death, 2018 (WHO, 2019)

Figure I Percentage of global cancer deaths according to cancer types. Estimated percentages of cancer deaths include both sexes and all age groups in 2018 Notes: Data source: WHO, GLOBOCAN, $2018 .^{2}$ 
Phytochemical-based anticancer drugs serve as low cost, less toxic, effective and promising against conventional chemotherapy. However, poor bioavailability, insufficient genotoxic profile, along with variable immune response creates an obstacle for its effective use in clinical trials. ${ }^{3}$ The discrepancy in various research outputs on mechanistic selectivity, allergic reactions, contaminants, drug-interactions, and safety needs to be addressed carefully before entering into the pharmaceutical market. Fully understanding anticancer drug mechanisms of action integrating experts from related/allied fields such as biology, medicine, physics, engineering, mathematics, etc., can be effective for tackling this global menace. Precise assessment of phytobioactive-drug conjugation, better bioavailability to the target tissue with advanced imaging tools to avoid over/under-diagnosis can forecast better theranostics outcomes creating a path for successful anticancer drug invention.

\section{Cell Cycle Checkpoints: Phyto- Compound-Driven Growth Seizure versus Apoptotic Cell Death}

Cell growth and proliferation proceed through different phases of the cell cycle such as growth phases (G1/G2), S-phase (DNA synthesis), and M-phase (mitosis). Also, the initial G0-phase (quiescent state) waiting a favorable time to enter the G1 phase (Figure 2). Five checkpoints of the cell cycle (represented by Red pause signs) restrict normal cell growth in response to external or internal defect stimuli. At the $\mathrm{G} 0 / \mathrm{G} 1$ cell checkpoint, the cell returns to the $\mathrm{G} 0$ state on DNA damage response. At the G1/S cell checkpoint, active growth and DNA replication are ceases. At S/G2 checkpoint chromosome replication and cell division is restricted, G2/M checkpoint accounts for DNA damage seizing cell at G2 phase, and M (metaphase-mitotic spindle) checkpoints followed by irreparable DNA damage, seizing the cell from further growing, and thus compelling cancer cells to undergo programmed cell death. ${ }^{4}$

Programmed cell death is a steadily regulated process and a distinctive form of cell death called 'Apoptosis', which has received remarkable attention in anticancer theranostics. The induction of apoptosis is regulated by intrinsic and extrinsic signaling pathways, as once apoptosis has initiated, it inevitably ends in the death of the cell. The intrinsic apoptotic pathway is also known as the mitochondrial pathway, where mitochondria play a key role, particularly via stress stimuli like ROS (reactive oxygen species) and RNS (reactive nitrogen species) releasing cytochrome-c by recruiting Bax and Bak proteins to the outer membrane of mitochondria. ${ }^{5}$ Once cytochrome-c leaks out, it binds the apoptotic factors to caspases creating apoptosome protein complex. The apoptosome activates the Caspase 3 and thereby apoptotic cell death. The extrinsic pathway is activated by extracellular tumor necrosis factor (TNF)-induced and First apoptosis signal (FAS)-ligand binding to the death receptors on cell-surface, further leads to the Caspase mediated apoptosis. ${ }^{6}$ In some cell types, DNA breaks into fragments and cell cycle arrests before entering apoptosis. Chemopreventives alone are highly toxic to non-cancerous cells and organs. Given in Figure 2, it demonstrates phytochemicals conjugated anticancer therapeutics can reduce cytotoxic effects to the surrounding normal cells of the tumor, initiating cell cycle arrest that leads to the cell death, hence effectively preventing tumor growth. Cell cycle checkpoints and apoptotic cell death are critically interlinked with the DNA damage/repair process, which is the central target for an effective anticancer therapeutics.${ }^{4,6}$ For example, topotecan, flavopiridol, elomotecan, and exatecan mesylate anhydrous are linked with inductions of apoptosis in several human cancer such as a malignant solid tumor, ovarian and small-cell lung cancers, central nervous system tumors, acute myeloid leukemia (AML), prostate cancer and kidney cancer. ${ }^{7-9}$ Vinflunine ditartrate and vincristine induce apoptosis activation through $\mathrm{G} 2 / \mathrm{S}$ and $\mathrm{G} 2 / \mathrm{M}$ phase arrest, substantially contributing to the inhibition of cancer growth (Figure 2, Table 2). Therefore, understanding the underlying molecular mechanism, inducing cell cycle checkpoint arrest, and targeting apoptotic cellular components could be promising for the discovery of effective chemopreventives.

\section{Phytochemicals as Cell Cycle Arrest and Apoptotic Cell Death Stimuli in Cancer Therapy}

Over centuries plant-based products have been used for various medicinal purposes worldwide. In recent years, phytochemicals are being extensively explored for their potential preventive effects against cancer. ${ }^{10-12}$ A wide spectrum of clinical trials has detected significant anticancer properties of various phytochemicals, which are currently in clinical use. ${ }^{13}$ As indicated in Figure 3, a wide array of secondary plant metabolites (phenols, alkaloids, flavonoids, flavonols, terpenoids, terpenes, steroids, 


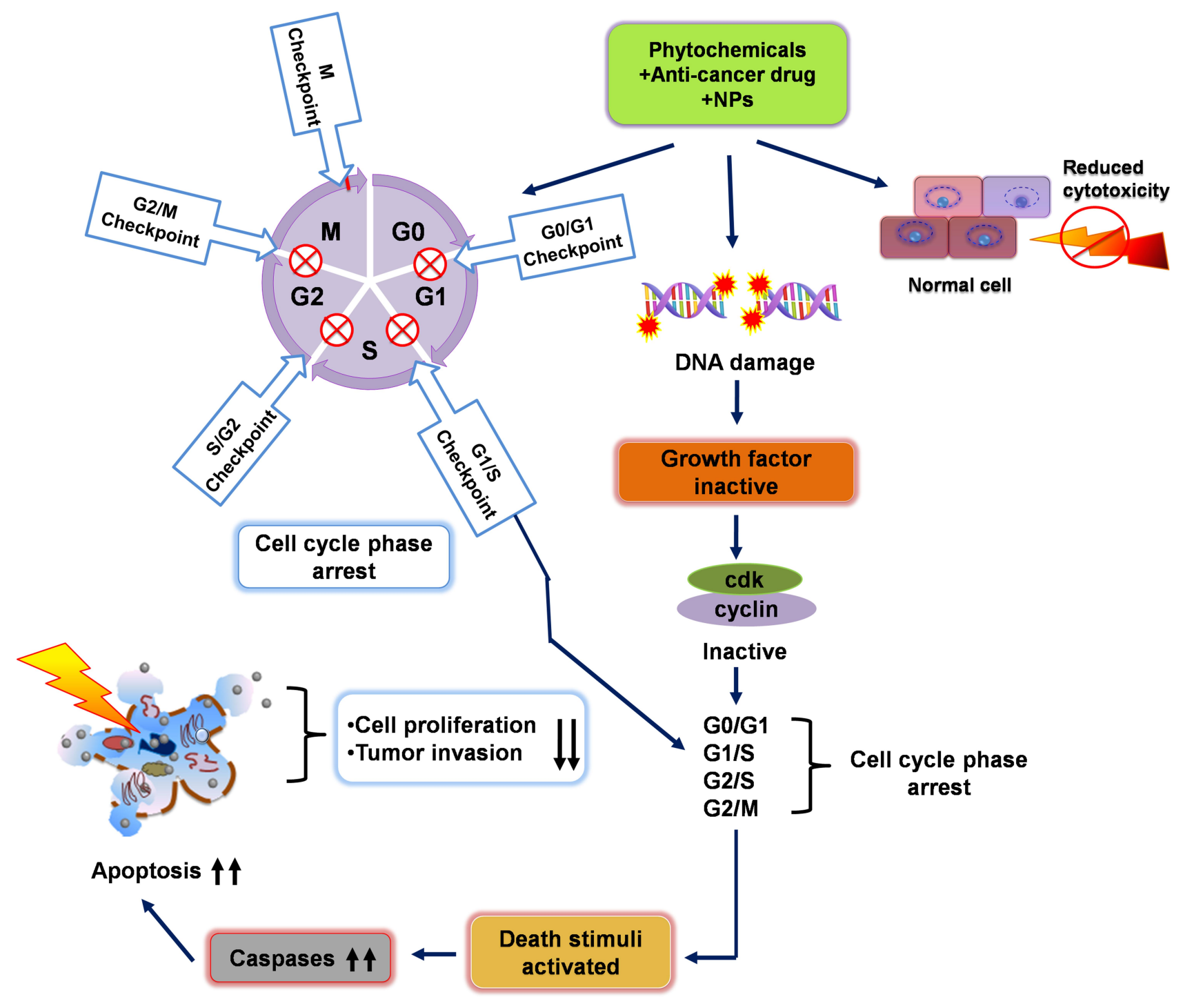

Figure 2 Phytochemicals inducing cancer cell growth arrest and cell death through cell cycle signaling checkpoint modulation. Phytochemicals induce cell cycle arrest at G0/ GI (resting phase, metabolically active), GI/S (active growth phase), S/G2 (chromosome replication and cell division), G2/M (DNA damage phase) and M (metaphase-mitotic spindle) checkpoints followed by irreparable DNA damage, seizing the cell from further growing, thus compelling cancer cells to undergo apoptosis process. Abbreviations: G0, Growth 0 resting phase; GI, Growth I active growth phase; S, Synthesis phase; G2, Growth 2 phase; M, mitotic metaphase.

flavonolignans, and organosulfur compounds) have been identified, isolated, characterized and investigated clinically for their use in cancer therapy (Figure 3). For example, phytobioactive compounds such as; epigallocatechin gallate (EGCG), a polyphenol isolated from Camellia sinensis (Tea); genistein, a soy isoflavonoid derived from Glycin max Linn.; sulforaphane, an organosulfur compound from isothiocyanate class; curcumin, another polyphenol extracted from Curcuma longa (turmeric), and vinorelbine tartrate, from Vinca rosea have been proven to have potent antineoplastic efficacy against an array cancer types (Figure 3 and Table 2). Accordingly, in recent years, antineoplastic phytochemicals (eg, phenyl ethyl ester, luteolin, kaempferol, sulforaphane, curcumin, genistein, dioscin, resveratrol, quercetin, curcumin, and capsaicin, etc.) have been evaluated for their efficacy and safe use in cancer theranostics (Figure 3). The anticancer potency of these plant-based phytocompounds has been associated with cell cycle modulation (Figure 2) such as inhibition of cell cycle checkpoints, activation of apoptotic signaling pathways (Figure 4) as well as induction of oxidative stress, activating caspase cascades, ultimately leading to cancer cell death. Furthermore, plant-based products decrease the cytotoxicity of the chemotherapeutic agent and can be loaded with higher volume which is crucial to attaining maximal and prolonged anticancer effect. ${ }^{14}$ 
Table 2 Phytochemical-Based Anticancer Drugs Currently on the Market in Clinical Trials and Clinical Use as Cell Cycle Arrest and Apoptotic Agents

\begin{tabular}{|c|c|c|c|c|c|}
\hline Phytochemicals & Plant Source & $\begin{array}{l}\text { Chemical } \\
\text { Formula }\end{array}$ & $\begin{array}{l}\text { Molecular } \\
\text { Weight (g/ } \\
\text { mol) }\end{array}$ & Chemical Structure & References* \\
\hline $\begin{array}{l}\text { Alvocidib } \\
\text { [Flavopiridol] }\end{array}$ & $\begin{array}{l}\text { Dysoxylumbinectariferum } \\
\text { (Meliaceae) }\end{array}$ & $\mathrm{C}_{21} \mathrm{H}_{20} \mathrm{CINO}_{5}$ & $401.8 \mathrm{~g} / \mathrm{mol}$ & & $\begin{array}{l}{[15]} \\
\text { NCT00003256 } \\
\text { NCT0044534I } \\
\text { NCT00058240 }\end{array}$ \\
\hline $\begin{array}{l}\text { Topotecan } \\
\text { [Hycamtin] }\end{array}$ & $\begin{array}{l}\text { Camptothecaacuminata } \\
\text { Decne } \\
\text { (Nyssaceae) }\end{array}$ & $\mathrm{C}_{23} \mathrm{H}_{23} \mathrm{~N}_{3} \mathrm{O}_{5}$ & $457.9 \mathrm{~g} / \mathrm{mol}$ & & $\begin{array}{l}{[\mathrm{l} 6]} \\
\text { NCT006II468 } \\
\text { NCT00382733 } \\
\text { NCT0I492673 }\end{array}$ \\
\hline $\begin{array}{l}\text { Belotecan } \\
\text { hydrochloride }\end{array}$ & $\begin{array}{l}\text { Camptothecaacuminata } \\
\text { Decne } \\
\text { (Nyssaceae) }\end{array}$ & $\mathrm{C}_{25} \mathrm{H}_{28} \mathrm{CIN}_{3} \mathrm{O}_{4}$ & $470 \mathrm{~g} / \mathrm{mol}$ & & $\begin{array}{l}{[\mathrm{I7]}} \\
\text { NCT00430I44 } \\
\text { NCT0I497873 } \\
\text { NCT0I6300I8 }\end{array}$ \\
\hline Irinotecan $\mathrm{HCl}$ & $\begin{array}{l}\text { Camptothecaacuminata } \\
\text { Decne } \\
\text { (Nyssaceae) }\end{array}$ & $\mathrm{C}_{33} \mathrm{H}_{39} \mathrm{CIN}_{4} \mathrm{O}_{6}$ & $623.1 \mathrm{~g} / \mathrm{mol}$ & & $\begin{array}{l}{[\mathrm{I} 8]} \\
\text { NCTOIII } 4555 \\
\text { NCT0I } 220063 \\
\text { NCT00003748 }\end{array}$ \\
\hline Gimatecan & $\begin{array}{l}\text { Camptotheca acuminate } \\
\text { (Nyssaceae) }\end{array}$ & $\mathrm{C}_{25} \mathrm{H}_{25} \mathrm{~N}_{3} \mathrm{O}_{5}$ & $447.5 \mathrm{~g} / \mathrm{mol}$ & & $\begin{array}{l}\text { NCT004I0358 } \\
\text { NCT00032903 } \\
\text { NCT04029909 }\end{array}$ \\
\hline
\end{tabular}

(Continued) 
Table 2 (Continued).

\begin{tabular}{|c|c|c|c|c|c|}
\hline Phytochemicals & Plant Source & $\begin{array}{l}\text { Chemical } \\
\text { Formula }\end{array}$ & $\begin{array}{l}\text { Molecular } \\
\text { Weight (g/ } \\
\text { mol) }\end{array}$ & Chemical Structure & References* \\
\hline $\begin{array}{l}\text { 9-amino-20(S)- } \\
\text { camptothecin } \\
\text { [9-amino-CPT] }\end{array}$ & $\begin{array}{l}\text { Camptotheca acuminate } \\
\text { (Nyssaceae) }\end{array}$ & $\mathrm{C}_{20} \mathrm{H}_{17} \mathrm{~N}_{3} \mathrm{O}_{4}$ & $363.4 \mathrm{~g} / \mathrm{mol}$ & & $\begin{array}{l}\text { NCT00002635 } \\
\text { NCT0000355 I } \\
\text { NCT0000267I }\end{array}$ \\
\hline $\begin{array}{l}\text { AR-67 } \\
\text { [10-Hydroxy } \\
\text { Camptothecin] }\end{array}$ & $\begin{array}{l}\text { Camptotheca acuminate } \\
\text { (Nyssaceae) }\end{array}$ & $\mathrm{C}_{20} \mathrm{H}_{16} \mathrm{~N}_{2} \mathrm{O}_{5}$ & $364.4 \mathrm{~g} / \mathrm{mol}$ & & $\begin{array}{l}{[19,20]} \\
\text { NCT00956787 } \\
\text { NCT0I } 202370 \\
\text { NCT00389480 }\end{array}$ \\
\hline $\begin{array}{l}\text { Karenitecin } \\
\text { [Cositecan] }\end{array}$ & $\begin{array}{l}\text { Camptotheca acuminate } \\
\text { (Nyssaceae) }\end{array}$ & $\mathrm{C}_{25} \mathrm{H}_{28} \mathrm{~N}_{2} \mathrm{O}_{4} \mathrm{Si}$ & $448.6 \mathrm{~g} / \mathrm{mol}$ & & $\begin{array}{l}\text { NCT00010218 } \\
\text { NCT00062478 } \\
\text { NCT00477282 }\end{array}$ \\
\hline $\begin{array}{l}\text { Exatecan mesylate } \\
\text { anhydrous }\end{array}$ & $\begin{array}{l}\text { Camptotheca acuminate } \\
\text { (Nyssaceae) }\end{array}$ & $\mathrm{C}_{25} \mathrm{H}_{26} \mathrm{FN}_{3} \mathrm{O}_{7} \mathrm{~S}$ & $531.6 \mathrm{~g} / \mathrm{mol}$ & & $\begin{array}{l}\text { NCT000453I8 } \\
\text { NCT00055939 } \\
\text { NCT0000509I }\end{array}$ \\
\hline $\begin{array}{l}\text { BN80927 } \\
\text { [Elomotecan] }\end{array}$ & $\begin{array}{l}\text { Camptotheca acuminate } \\
\text { (Nyssaceae) }\end{array}$ & $\mathrm{C}_{29} \mathrm{H}_{32} \mathrm{CIN}_{3} \mathrm{O}_{4}$ & $558.5 \mathrm{~g} / \mathrm{mol}$ & & NCT0I435096 \\
\hline
\end{tabular}

(Continued) 
Table 2 (Continued).

\begin{tabular}{|c|c|c|c|c|c|}
\hline Phytochemicals & Plant Source & $\begin{array}{l}\text { Chemical } \\
\text { Formula }\end{array}$ & $\begin{array}{l}\text { Molecular } \\
\text { Weight (g/ } \\
\text { mol) }\end{array}$ & Chemical Structure & References* \\
\hline $\begin{array}{l}\text { Namitecan } \\
\text { [ST-1968] }\end{array}$ & $\begin{array}{l}\text { Camptotheca acuminate } \\
\text { (Nyssaceae) }\end{array}$ & $\mathrm{C}_{23} \mathrm{H}_{22} \mathrm{~N}_{4} \mathrm{O}_{5}$ & $434.4 \mathrm{~g} / \mathrm{mol}$ & & NCT0I748019 \\
\hline $\begin{array}{l}\text { 5-(2'- } \\
\text { Hydroxyethoxy)-20 } \\
\text { (S)-camptothecin } \\
\text { [DRF-I042] }\end{array}$ & $\begin{array}{l}\text { Camptotheca acuminate } \\
\text { (Nyssaceae) }\end{array}$ & $\mathrm{C}_{22} \mathrm{H}_{20} \mathrm{~N}_{2} \mathrm{O}_{6}$ & $434.4 \mathrm{~g} / \mathrm{mol}$ & & [2I] \\
\hline $\begin{array}{l}\text { Vincristine sulfate } \\
\text { [Kyocristine] }\end{array}$ & $\begin{array}{l}\text { Vinca rosea Linn. } \\
\text { (Apocynaceae) }\end{array}$ & $\mathrm{C}_{46} \mathrm{H}_{58} \mathrm{~N}_{4} \mathrm{O}_{14} \mathrm{~S}$ & $923 \mathrm{~g} / \mathrm{mol}$ & & $\begin{array}{l}{[22]} \\
\text { NCT00022555 } \\
\text { NCT005I } 6295\end{array}$ \\
\hline Vinorelbine tartrate & $\begin{array}{l}\text { Vinca rosea } \\
\text { (Apocynaceae) }\end{array}$ & $\mathrm{C}_{53} \mathrm{H}_{66} \mathrm{~N}_{4} \mathrm{O}_{20}$ & $1079.1 \mathrm{~g} / \mathrm{mol}$ & & $\begin{array}{l}{[23,24]} \\
\text { NCT00432562 } \\
\text { NCT00675597 } \\
\text { NCT0I 2227I5 }\end{array}$ \\
\hline $\begin{array}{l}\text { Vinflunine ditartrate } \\
\text { [Javlor] }\end{array}$ & $\begin{array}{l}\text { Vinca rosea } \\
\text { (Apocynaceae) }\end{array}$ & $\mathrm{C}_{53} \mathrm{H}_{66} \mathrm{~F}_{2} \mathrm{~N}_{4} \mathrm{O}_{20}$ & $1117.1 \mathrm{~g} / \mathrm{mol}$ & & $\begin{array}{l}{[25,26]} \\
\text { NCT00545766 } \\
\text { NCT00284I54 } \\
\text { NCT02347332 }\end{array}$ \\
\hline
\end{tabular}

(Continued) 
Table 2 (Continued).

\begin{tabular}{|c|c|c|c|c|c|}
\hline Phytochemicals & Plant Source & $\begin{array}{l}\text { Chemical } \\
\text { Formula }\end{array}$ & $\begin{array}{l}\text { Molecular } \\
\text { Weight (g/ } \\
\text { mol) }\end{array}$ & Chemical Structure & References* \\
\hline $\begin{array}{l}\text { Fosbretabulin } \\
\text { tromethamine } \\
\text { [CA4P] }\end{array}$ & $\begin{array}{l}\text { Combretum caffrum } \\
\text { (Combretaceae) }\end{array}$ & $\mathrm{C}_{18} \mathrm{H}_{19} \mathrm{Na}_{2} \mathrm{O}_{8} \mathrm{P}$ & $517.5 \mathrm{~g} / \mathrm{mol}$ & & $\begin{array}{l}{[27]} \\
\text { NCT013052। } 3 \\
\text { NCT02 I } 32468 \\
\text { NCT00653939 }\end{array}$ \\
\hline $\begin{array}{l}\text { Ombrabulin } \\
\text { [AVE8062] }\end{array}$ & $\begin{array}{l}\text { Combretum caffrum } \\
\text { (Combretaceae) }\end{array}$ & $\mathrm{C}_{21} \mathrm{H}_{26} \mathrm{~N}_{2} \mathrm{O}_{6}$ & $402.4 \mathrm{~g} / \mathrm{mol}$ & & $\begin{array}{l}{[28]} \\
\text { NCT006995I } 7 \\
\text { NCT0I } 907685 \\
\text { NCT0I } 263886\end{array}$ \\
\hline $\begin{array}{l}\text { Idronoxil } \\
\text { [Phenoxodiol] }\end{array}$ & $\begin{array}{l}\text { Glycine max Linn. } \\
\text { (Fabaceae) }\end{array}$ & $\mathrm{C}_{15} \mathrm{H}_{12} \mathrm{O}_{3}$ & $240.2 \mathrm{~g} / \mathrm{mol}$ & & $\begin{array}{l}{[29-3 \text { I }]} \\
\text { NCT003828I I } \\
\text { NCT00557037 } \\
\text { NCT003828I I }\end{array}$ \\
\hline Genistein & $\begin{array}{l}\text { Glycin max Linn. } \\
\text { (Fabaceae) }\end{array}$ & $\mathrm{C}_{15} \mathrm{H}_{10} \mathrm{O}_{5}$ & $270.2 \mathrm{~g} / \mathrm{mol}$ & & $\begin{array}{l}{[10,32]} \\
\text { NCT0I985763 } \\
\text { NCT0I3253II } \\
\text { NCT00244933 }\end{array}$ \\
\hline $\begin{array}{l}\text { Ingenolmebutate } \\
\text { [PEP 005] }\end{array}$ & $\begin{array}{l}\text { Euphorbia peplus } \\
\text { (Euphorbiaceae) }\end{array}$ & $\mathrm{C}_{25} \mathrm{H}_{34} \mathrm{O}_{6}$ & $430.5 \mathrm{~g} / \mathrm{mol}$ & & $\begin{array}{l}{[33]} \\
\text { NCT03569345 } \\
\text { NCT00 I08I2 I } \\
\text { NCT0272372 I }\end{array}$ \\
\hline Betulinic acid & $\begin{array}{l}\text { Betula pubescens } \\
\text { (Betulaceae) }\end{array}$ & $\mathrm{C}_{30} \mathrm{H}_{48} \mathrm{O}_{3}$ & $456.7 \mathrm{~g} / \mathrm{mol}$ & & $\begin{array}{l}{[34]} \\
\text { NCT0070I987 }\end{array}$ \\
\hline
\end{tabular}

(Continued) 
Table 2 (Continued).

\begin{tabular}{|c|c|c|c|c|c|}
\hline Phytochemicals & Plant Source & $\begin{array}{l}\text { Chemical } \\
\text { Formula }\end{array}$ & $\begin{array}{l}\text { Molecular } \\
\text { Weight (g/ } \\
\text { mol) }\end{array}$ & Chemical Structure & References* \\
\hline Maytansine & $\begin{array}{l}\text { Maytenusovatus } \\
\text { (Celastraceae) }\end{array}$ & $\mathrm{C}_{34} \mathrm{H}_{46} \mathrm{CIN}_{3} \mathrm{O}_{10}$ & $692.2 \mathrm{~g} / \mathrm{mol}$ & & $\begin{array}{l}{[35]} \\
\text { NCT02289833 } \\
\text { NCT00934856 } \\
\text { NCT0I64I939 }\end{array}$ \\
\hline Sulforaphane & $\begin{array}{l}\text { Brassica oleracea } \\
\text { (Brassicaceae) }\end{array}$ & $\mathrm{C}_{6} \mathrm{H}_{11} \mathrm{NOS}_{2}$ & $177.3 \mathrm{~g} / \mathrm{mol}$ & & $\begin{array}{l}{[36]} \\
\text { NCT03232I } 38 \\
\text { NCT0I } 228084 \\
\text { NCT02970682 }\end{array}$ \\
\hline $\begin{array}{l}\text { Epigallocatechin } \\
\text { gallate } \\
\text { [EGCG] }\end{array}$ & $\begin{array}{l}\text { Camellia sinensis } \\
\text { (Theaceae) }\end{array}$ & $\mathrm{C}_{22} \mathrm{H}_{18} \mathrm{O}_{11}$ & $458.4 \mathrm{~g} / \mathrm{mol}$ & & $\begin{array}{l}{[37]} \\
\text { NCT0289I538 } \\
\text { NCT02577393 } \\
\text { NCT00459407 }\end{array}$ \\
\hline Curcumin & $\begin{array}{l}\text { Curcuma longa } \\
\text { (Zingiberaceae) }\end{array}$ & $\mathrm{C}_{21} \mathrm{H}_{20} \mathrm{O}_{6}$ & $368.3 \mathrm{~g} / \mathrm{mol}$ & & $\begin{array}{l}{[38]} \\
\text { NCTOI9I } 7890 \\
\text { NCTOI } 160302 \\
\text { NCT02554344 }\end{array}$ \\
\hline $\begin{array}{l}\text { R-(-)-Gossypol acetic } \\
\text { acid }\end{array}$ & $\begin{array}{l}\text { Gossypium herbaceum } \\
\text { (Malvaceae) }\end{array}$ & $\mathrm{C}_{32} \mathrm{H}_{34} \mathrm{O}_{10}$ & $578.6 \mathrm{~g} / \mathrm{mol}$ & & $\begin{array}{l}{[39]} \\
\text { NCT00773955 } \\
\text { NCT00397293 } \\
\text { NCT00666666 }\end{array}$ \\
\hline $\begin{array}{l}\text { Beta-lapachone } \\
\text { [ARQ 50I] }\end{array}$ & $\begin{array}{l}\text { Tabebuia avellanedae } \\
\text { (Bignoniaceae) }\end{array}$ & $\mathrm{C}_{15} \mathrm{H}_{14} \mathrm{O}_{3}$ & $242.2 \mathrm{~g} / \mathrm{mol}$ & & $\begin{array}{l}{[40]} \\
\text { NCT00524524 } \\
\text { NCT00099190 } \\
\text { NCT00358930 }\end{array}$ \\
\hline
\end{tabular}

(Continued) 
Table 2 (Continued).

\begin{tabular}{|c|c|c|c|c|c|}
\hline Phytochemicals & Plant Source & $\begin{array}{l}\text { Chemical } \\
\text { Formula }\end{array}$ & $\begin{array}{l}\text { Molecular } \\
\text { Weight (g/ } \\
\text { mol) }\end{array}$ & Chemical Structure & References* \\
\hline $\begin{array}{l}\text { Cryptophycins } 52 \\
\text { [LY355703] }\end{array}$ & $\begin{array}{l}\text { Cyanobacteria, Nostoc sp. } \\
\text { [ATCC 53,789,Nostoc } \\
\text { sp. GSV 224] } \\
\text { (Nostocaceae) }\end{array}$ & $\mathrm{C}_{36} \mathrm{H}_{45} \mathrm{CIN}_{2} \mathrm{O}_{8}$ & $669.2 \mathrm{~g} / \mathrm{mol}$ & & {$[41,42]$} \\
\hline Lovastatin & $\begin{array}{l}\text { Pleurotusostreatus } \\
\text { (Pleurotaceae) }\end{array}$ & $\mathrm{C}_{24} \mathrm{H}_{36} \mathrm{O}_{5}$ & $404.5 \mathrm{~g} / \mathrm{mol}$ & & $\begin{array}{l}\text { NCT00462280 } \\
\text { NCT005840I2 } \\
\text { NCT00902668 }\end{array}$ \\
\hline $\begin{array}{l}\text { Kanglaite } \\
\text { [Coix Seed Oil] }\end{array}$ & $\begin{array}{l}\text { Coixlacryma-jobi } \\
\text { (Cramineae) }\end{array}$ & NA & NA & NA & $\begin{array}{l}{[43]} \\
\text { NCT02553187 } \\
\text { NCT03986528 } \\
\text { NCT00733850 }\end{array}$ \\
\hline Simvastatin & $\begin{array}{l}\text { Aspergillus terreus } \\
\text { (Trichocomaceae) }\end{array}$ & $\mathrm{C}_{25} \mathrm{H}_{38} \mathrm{O}_{5}$ & $418.5 \mathrm{~g} / \mathrm{mol}$ & & $\begin{array}{l}{[44]} \\
\text { NCT03324425 } \\
\text { NCT00334542 } \\
\text { NCT00944463 }\end{array}$ \\
\hline $\begin{array}{l}\text { Paclitaxel } \\
\text { [TAXOL] }\end{array}$ & $\begin{array}{l}\text { Taxus brevifolia } \\
\text { (Taxaceae) }\end{array}$ & $\mathrm{C}_{47} \mathrm{H}_{51} \mathrm{NO}_{14}$ & $853.9 \mathrm{~g} / \mathrm{mol}$ & & [45] \\
\hline $\begin{array}{l}\text { Taxoprexin } \\
\text { [DHA-paclitaxel] }\end{array}$ & $\begin{array}{l}\text { Taxus brevifolia } \\
\text { (Taxaceae) }\end{array}$ & $\mathrm{C}_{69} \mathrm{H}_{81} \mathrm{NO}_{15}$ & $1164.3 \mathrm{~g} / \mathrm{mol}$ & & $\begin{array}{l}{[46]} \\
\text { NCT002448I6 } \\
\text { NCT00249262 } \\
\text { NCT00243867 }\end{array}$ \\
\hline
\end{tabular}

(Continued) 
Table 2 (Continued).

\begin{tabular}{|c|c|c|c|c|c|}
\hline Phytochemicals & Plant Source & $\begin{array}{l}\text { Chemical } \\
\text { Formula }\end{array}$ & $\begin{array}{l}\text { Molecular } \\
\text { Weight (g/ } \\
\text { mol) }\end{array}$ & Chemical Structure & References* \\
\hline $\begin{array}{l}\text { Larotaxel } \\
{[\text { XRP 988I] }}\end{array}$ & $\begin{array}{l}\text { Taxus baccata L. } \\
\text { (Taxaceae) }\end{array}$ & $\mathrm{C}_{45} \mathrm{H}_{53} \mathrm{NO}_{14}$ & $831.9 \mathrm{~g} / \mathrm{mol}$ & & $\begin{array}{l}{[47]} \\
\text { NCT00387907 } \\
\text { NCT004I7209 } \\
\text { NСT00625664 }\end{array}$ \\
\hline $\begin{array}{l}\text { Ortataxel [IDN- } \\
\text { 5109/BAY 59-8862] }\end{array}$ & $\begin{array}{l}\text { Taxus baccata L. } \\
\text { (Taxaceae) }\end{array}$ & $\mathrm{C}_{44} \mathrm{H}_{57} \mathrm{NO}_{17}$ & $871.9 \mathrm{~g} / \mathrm{mol}$ & & $\begin{array}{l}{[48]} \\
\text { NСT0I989884 } \\
\text { NCT000543।4 } \\
\text { NСT00039I69 }\end{array}$ \\
\hline $\begin{array}{l}\text { MAC 32I } \\
\text { [Milataxel] }\end{array}$ & $\begin{array}{l}\text { Taxus baccata } \mathrm{L} \text {. } \\
\text { (Taxaceae) }\end{array}$ & $\mathrm{C}_{44} \mathrm{H}_{55} \mathrm{NO}_{16}$ & $853.9 \mathrm{~g} / \mathrm{mol}$ & & $\begin{array}{l}{[49]} \\
\text { NCT00685204 } \\
\text { NCT00063219 } \\
\text { NСT00063427 }\end{array}$ \\
\hline $\begin{array}{l}\text { UNII-A2VM2V569A } \\
\text { [TPI-287] }\end{array}$ & $\begin{array}{l}\text { Taxus baccata } \mathrm{L} \text {. } \\
\text { (Taxaceae) }\end{array}$ & $\mathrm{C}_{46} \mathrm{H}_{63} \mathrm{NO}_{15}$ & $869.9 \mathrm{~g} / \mathrm{mol}$ & & {$[50,5 I]$} \\
\hline $\begin{array}{l}\text { BMS-275, I83 } \\
\text { [Oral Taxane] }\end{array}$ & $\begin{array}{l}\text { Taxus baccata } \mathrm{L} \text {. } \\
\text { (Taxaceae) }\end{array}$ & $\mathrm{C}_{43} \mathrm{H}_{59} \mathrm{NO}_{16}$ & $845.9 \mathrm{~g} / \mathrm{mol}$ & & NCT00I0383I \\
\hline
\end{tabular}

(Continued) 
Table 2 (Continued).

\begin{tabular}{|c|c|c|c|c|c|}
\hline Phytochemicals & Plant Source & $\begin{array}{l}\text { Chemical } \\
\text { Formula }\end{array}$ & $\begin{array}{l}\text { Molecular } \\
\text { Weight (g/ } \\
\text { mol) }\end{array}$ & Chemical Structure & References* \\
\hline $\begin{array}{l}\text { DJ } 927 \\
\text { [Tesetaxel] }\end{array}$ & $\begin{array}{l}\text { Taxus baccata L. } \\
\text { (Taxaceae) }\end{array}$ & $\mathrm{C}_{46} \mathrm{H}_{60} \mathrm{FN}_{3} \mathrm{O}_{13}$ & $882 \mathrm{~g} / \mathrm{mol}$ & & $\begin{array}{l}{[52]} \\
\text { NCT0 } 064713 \\
\text { NCT00077077 } \\
\text { NCT0I573468 }\end{array}$ \\
\hline $\begin{array}{l}\text { Cabazitaxel } \\
\text { [Jevtana] }\end{array}$ & $\begin{array}{l}\text { Taxus brevifolia Nutt. } \\
\text { (Taxaceae) }\end{array}$ & $\mathrm{C}_{45} \mathrm{H}_{57} \mathrm{NO}_{14}$ & $835.93 \mathrm{~g} / \mathrm{mol}$ & & $\begin{array}{l}{[53]} \\
\text { NCT0I } 751308 \\
\text { NCT0I } 438307 \\
\text { NCTOI } 308580\end{array}$ \\
\hline $\begin{array}{l}\text { Elliptinium acetate } \\
\text { [Celiptium] }\end{array}$ & $\begin{array}{l}\text { Bleekeriavitensis } \\
\text { (Apocynaceae) }\end{array}$ & $\mathrm{C}_{20} \mathrm{H}_{20} \mathrm{~N}_{2} \mathrm{O}_{3}$ & $336.4 \mathrm{~g} / \mathrm{mol}$ & & [54] \\
\hline $\begin{array}{l}\text { Omacetaxine } \\
\text { mepesuccinate } \\
\text { [Synribo] }\end{array}$ & $\begin{array}{l}\text { Cephalotaxusharringtonia } \\
\text { var. drupacea } \\
\text { (Cephalotaxaceae) }\end{array}$ & $\mathrm{C}_{29} \mathrm{H}_{39} \mathrm{NO}_{9}$ & $582.1 \mathrm{~g} / \mathrm{mol}$ & & $\begin{array}{l}{[55]} \\
\text { NCT00006364 } \\
\text { NCT00462943 } \\
\text { NCT00675350 }\end{array}$ \\
\hline
\end{tabular}

Notes: ${ }^{\#}$ Source: US National Library of Medicine. ${ }^{*}$ www.clinicaltrials.gov.

In recent years, combinatorial therapy is being used in clinics in which phytocompounds are used in conjugation with other chemopreventives to achieve higher cancer sensitivity compared to single drugs. ${ }^{13,14}$ To date, more than hundreds of phytochemicals (eg, topotecan, irinotecan $\mathrm{HCl}$, vincristine sulfate, vinorelbine tartrate, vinflunine ditartrate, ingenol mebutate, maytansine, sulforaphane, curcumin, paclitaxel, etc.) have been approved by US FDA and currently, in clinical use as potent anticancer drugs, ${ }^{2,7}$ compiled in Table 2 . Numerous clinical data suggest that these phytochemicals combat cancer via cell cycle arrest and apoptosis with less systemic toxicity further improving human life. Further, integrating green nanotechnology into cancer science to formulate superior plant-based antineoplastic agents has become an imperative research area for pharmaceutical and biomedical sciences. ${ }^{3,10}$ In this section, a detailed update on antineoplastic phytochemicals, plant source, family, and their specific molecular formula along with structure is given (Table 2). Furthermore, natural anticancer phytochemicals currently under clinical trials and clinical use according to their potency through cell cycle arrest and apoptosis mechanism have been discussed. 


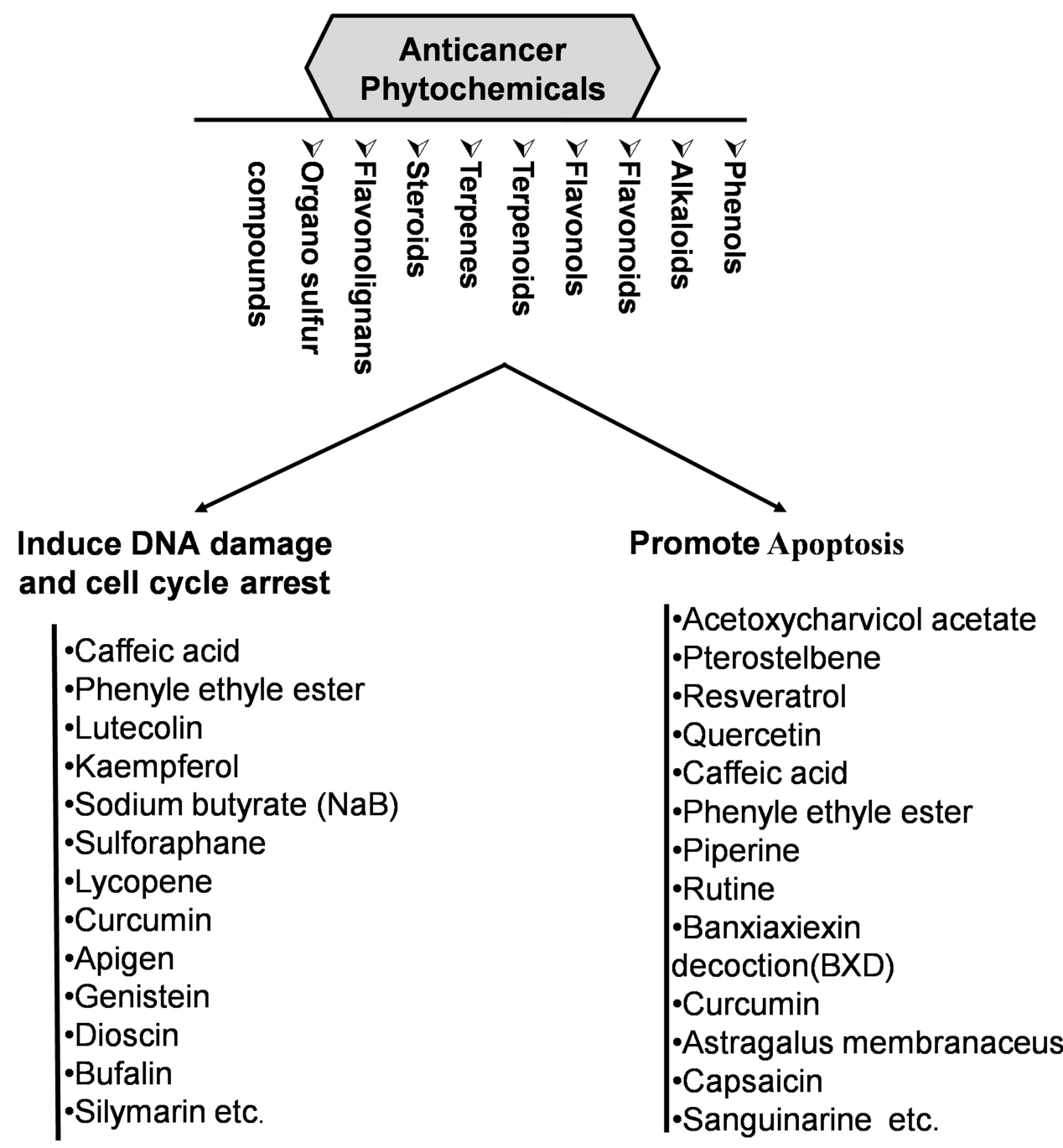

Figure 3 Anticancer phytochemicals inducing DNA damage and cell cycle growth seizure progressing apoptosis for tumor clearance.

\section{Alvocidib [Flavopiridol]}

Alvocidib is formerly known as Flavopiridol, is a flavone compound of 3-hydroxy-1-methyl piperidine chlorophenyl, extracted from Indian plant Dysoxylum binectariferum (Meliaceae family), with antineoplastic efficacy. It also works by inhibiting CDK9 with cyclindependent kinases (CDKs) inhibitor by halting phosphorylation, arresting cell cycle at G1phase, and progressing for apoptosis. A multicentre (10 institutions involved) randomized Phase II clinical trial of avlocidib followed by cytarabine and mitoxantrone (FLAM) was conducted taking 165 patients of high-risk AML (18-70 yrs) of FLAM $(\mathrm{n}=109)$ and induction of $7+3$ $(\mathrm{n}=56)$. This trial resulted in increased complete response (CR) rates despite an insignificant overall survival rate (OS) and cytogenic toxicity. ${ }^{15}$ As a cell growth inhibitor and apoptosis inducer, it has been under phase-I/II clinical trial for acute myeloid leukemia, prostate cancer, and kidney cancer treatment [NCT00003256, NCT00445341, and NCT00058240]. These ongoing clinical trials will reach to produce substantial favorable results of avlocidib enhancing AML treatment outcomes.

\section{Topotecan [Hycamtin]}

Topotecan (Hycamtin) is a camptothecin analog extracted from the tree Camptotheca acuminata Decne (Nyssaceae) bark and is a topoisomerase-I inhibitor. This drug is used as an antineoplastic agent and has been approved by the FDA for the treatment of ovarian cancer (1996), cervical cancer (2006), and small cell lung cancer (2007). Recently, 398 studies have been registered under US Govt. clinical trial for various cancer therapy. ${ }^{16}$ In physiological ambiance, topotecan with its active lactone form interpolate with 


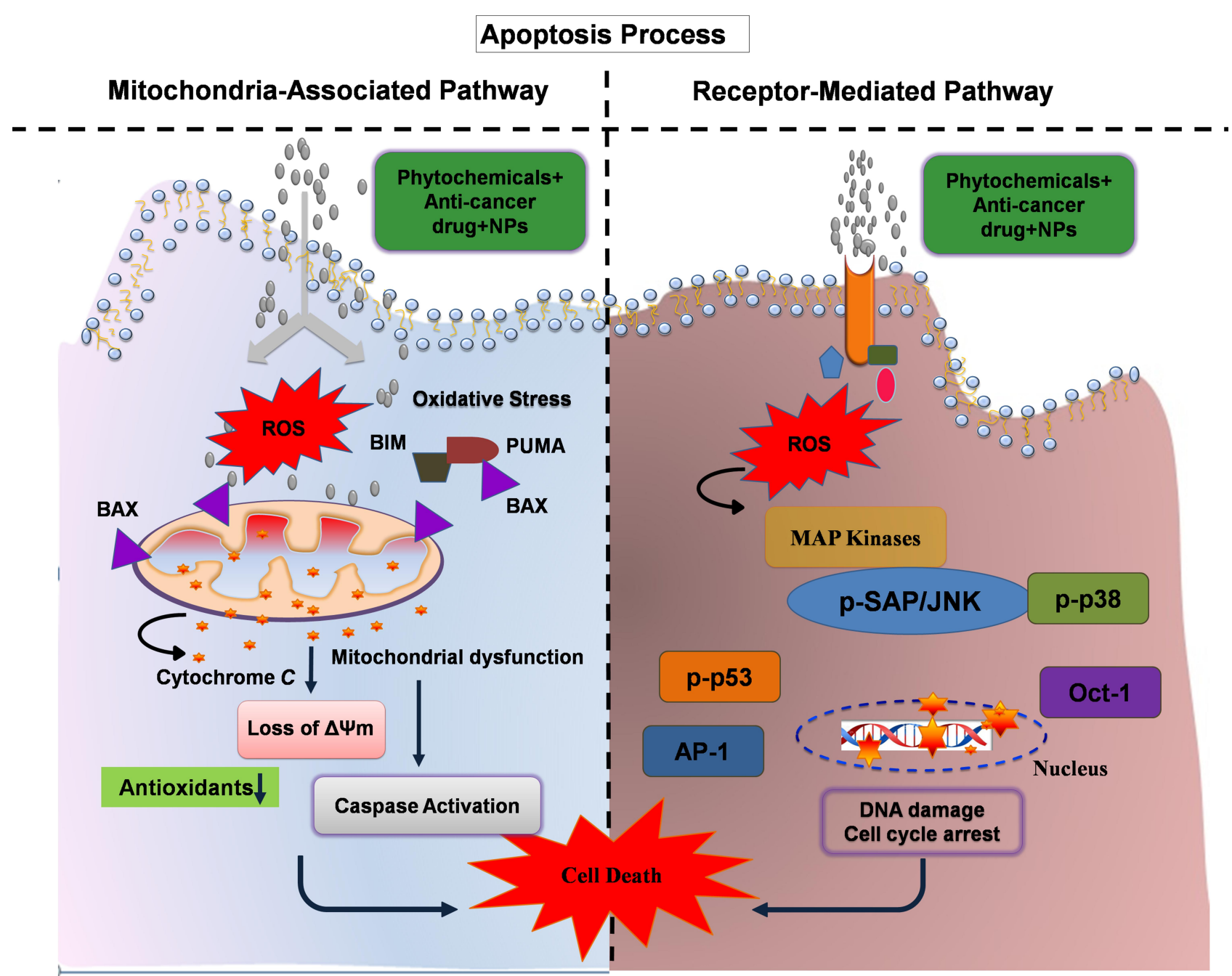

Figure 4 Intrinsic and extrinsic apoptotic cancer cell death mechanism with the treatment of phyto-nanocomposite inducing DNA damage and cell cycle arrest. Phytochemicals in combination with nanoparticles and anticancer drugs produce excessive ROS inducing oxidative stress that results in cancer cell death triggering various signaling pathways via mitochondrial and receptor-mediated apoptosis.

topoisomerase-I/DNA cleavage complex, further damaging DNA strand, disrupts cell cycle, and forcing cancer cells to undergo apoptotic death. ${ }^{16}$ Topotecan is either given alone or in combination for the treatment of ovarian and smallcell lung cancers and central nervous system tumors [NCT00611468, NCT00382733, and NCT01492673].

\section{Belotecan Hydrochloride}

Belotecan hydrochloride is a camptothecin analog with potential antineoplastic activity. Belotecan disrupts DNA replication, and induce cell cycle arrest compelling the tumor cells to undergo an apoptotic process of cell death. A multi-center (including 14 centers) randomized, openlabel Phase III clinical trial was conducted to compare the treatment outcome of belotecan/cisplatin (BP) with the conventional therapy of etoposide/cisplatin (EP) in naïve extensive-stage small cell lung carcinoma (ES-SCLC) patients. About 157 number of patients grouping into BP $(n=71)$ and EP $(n=76)$ were recruited for the trial. Results show BP arm had CR in one patient, partial response (PR) in 41, with stable disease (SD) response rate in 17 patients. However, non-inferior OS and PFS were found in both the EP and BP treatment arms. BP treatment regimen had raised concerns of grade 3 and 4 anemia along with thrombocytopenia, which suggests careful use of BP arm in further clinical trials. ${ }^{17}$ This drug is currently on clinical trials for the treatment of cervical cancers, small cell lung cancer, lung cancers, and ovarian cancer [NCT00430144, NCT01497873, and NCT01630018]. 


\section{Irinotecan $\mathrm{HCl}$ [Topotecin]}

Irinotecan hydrochloride (Topotecin) is a quinoline-based alkaloid and hydrochloride salt analog of natural product camptothecin. This drug forms active SN 38 (7-ethyl-10hydroxy-camptothecin) metabolite which is 1000 fold more effective in inducing cell cycle arrest at S-G2 phase and apoptosis compared to the parent drug. This drug appears to stabilize reversibly topoisomerase complex acting as topoisomerase inhibitor, halting DNA ligation by breaking DNA single-strand resulting in irreversible blockage of DNA synthesis, causing cancer cell death. CAMPTOSAR ${ }^{\circledR}$ (Irinotecan HCL) injection is approved by the US FDA, in 2004, for the therapeutic application of metastatic colorectal cancer (CRC) as a combinatorial intravenous therapy with 5-fluorouracil (5-FU)/leucovorin. ${ }^{18}$ After several phase III clinical studies, the most frequent dosing of irinotecan treatment is an intravenous infusion of $300-350 \mathrm{mg} /$ $\mathrm{m}^{2}$ for 30-90mn weekly for 6 weeks of the treatment cycle. Surprisingly, irinotecan has increased the OS (over 30months) of metastatic CRC patients dramatically, acting as a key anticancer regimen in combinatorial therapy with 5-FU. However, irinotecan-related drug toxicity can be overcome by lowering dose concentration in older and organ dysfunction cancer patients. ${ }^{18}$ This prodrug is used in combination or alone for the treatment of colorectal cancers, small cell lung cancer, and gastric cancer patients [NCT01114555, NCT01220063, and NCT00003748].

\section{Gimatecan [STI48I]}

Gimatecan is a lipophilic semisynthetic derivative of camptothecin, with potential antitumor activities. Gimatecan, an orally active topoisomerase-I inhibitor, apoptotic inducer, currently under clinical trials for the treatment of brain and central nervous system tumors, advanced solid tumors, advanced epithelial ovarian, peritoneal and fallopian tube cancer [NCT00410358, NCT00032903, and NCT04029909].

\section{9-Amino-20(S)-Camptothecin [9-Amino- CPT]}

9-Aminocamptothecin is a camptothecin derivative of water-soluble pyranoindolizinoquinoline, with antineoplastic activities. The 9-amino-CPT drug is under clinical trials for the treatment of gastric cancer, ovarian cancer, lung, and kidney cancer [NCT00002635, NCT00003551, and NCT00002671] as an inhibitor of cell cycle and inducer of apoptosis.

\section{0-Hydroxy Camptothecin [AR67]}

AR-67 (7-t-butyldimethylsilyl-10-hydroxycamptothecin) is a pyranoindolizinoquinoline of natural plant-based camptothecin analog, which is highly potent, lipophilic and prolonged stable in blood. AR67 is a potent anticancer drug inducing DNA damage and apoptosis and is well tolerated by cancer patients. A Phase I clinical study using thirdgeneration novel lactone form AR-67 with a dose of 1.2$12.4 \mathrm{mg} / \mathrm{m}^{2}$, daily infused for $1 \mathrm{hr}$ for 5 days, every 21 days cycle, conducted in refractory solid tumor patients. The results show that AR67 drug was well tolerated without any infusional allergic reactions and diarrhea and highly stable ( $87 \%$ of the total drug-infused) in blood as active lactone form. Partial response (PR) was noted for a longer period in non-small cell lung cancer (NSCLC) patient and stable disease (SD) was observed in NSCLC, small cell lung cancer (SCLC), and duodenal cancer. However, accepted toxicity of febrile neutropenia, exhaustion, thrombocytopenia were observed, which were limited with reduced dose concentration to $7.5 \mathrm{mg} / \mathrm{m}^{2}$ for every cycle of the treatment protocol. ${ }^{20}$ Several clinical trials were ongoing in glioblastoma multiforme and metastatic solid malignancy patients to further warrant therapeutic efficacy of AR67 [NCT00956787, NCT01202370, and NCT00389480].

\section{Karenitecin [Cositecan]}

Karenitecin is a lipophilic, silicon-containing camptothecin derivative, with antineoplastic activities. It is under clinical trials for the treatment of ovarian cancer, brain tumors, nonsmall cell lung cancer, because of its higher stability, higher bio-availability, and enhanced tumor tissue penetration ability compared to the parent drug [NCT00010218, NCT00062478, and NCT00477282]. It blocks the cell cycle and induces apoptosis in cancer tissues.

\section{Exatecan Mesylate Anhydrous [Mesylate]}

Exatecan Mesylate is a water-soluble camptothecin derivative, with potent antitumor activity. Mesylate is a topoisomerase-I inhibitor, damages DNA triggering apoptosis in cancer cells. This agent is under clinical trials for the treatment of pancreatic cancer, refractory rhabdomyosarcoma, non-small cell lung cancer [NCT00045318, NCT00055939, and NCT00005091].

\section{Elomotecan [BN80927]}

Elomotecan is a camptothecin analog of having a stable $\beta$ hydroxy lactone ring, with antineoplastic activities. 
Elomotecan is under clinical trial, a very potent antiproliferative agent used to treat cancer specifically malignant solid tumors [NCT01435096].

\section{Namitecan [ST-1968]}

Namitecan is a camptothecin analog, which has been used in clinical trials studying the treatment of Solid Tumors [NCT01748019]. This anticancer drug has S-phase specificity to inhibit cell cycle and induce apoptosis.

\section{DRF-I 042 [5-(2'-Hydroxyethoxy)-20(S)- Camptothecin]}

DRF-1042 is a derivative of camptothecin, with antineoplastic properties. This drug has cell cycle inhibition and apoptotic activities. A phase I clinical trial on the dose-escalation experiment of DRF-1042 was conducted in refractory solid tumor patients. DRF-1042 was administered at a dose concentration of 1.5 to $270 \mathrm{mg} / \mathrm{m}^{2}$, daily for 5day, every 2 weeks for 21 days. Results show $2 \mathrm{CR}, 2 \mathrm{PR}$, and $4 \mathrm{SD}$, but with delayed toxicity of grade 4 diarrhea and myelosuppression. The half-life of the drug found to be $9.9 \mathrm{~h}-29 \mathrm{~h}$. The recommended dose of phase II trial is $80 \mathrm{mg} / \mathrm{m}^{2}$ daily as per the treatment protocol. DRF-1042 is used in a phase-I trial for the treatment of prostate, colon, lung, and kidney tumors and has shown effective anticancer effect undergoing phase-II trials. $^{21}$

\section{Vincristine Sulfate [Kyocristine]}

Vincristine Sulfate is a natural alkaloid extracted from the plant Vinca rosea Linn. (Apocynaceae) with potent antineoplastic efficacy. Vincristine has antimitotic properties, depolymerizes microtubules further arresting tumor cells in S-phase and M-phase of the cell cycle. This drug is used as a major chemotherapy regimen, that works in versatile ways to control the growth of cancer cells, either by apoptotic cell death or by cell cycle phase arrest, stopping the cell division process. Vincristine is approved by the US FDA, in 1963, as Oncovin, for the treatment of leukemias such as lymphoblastic lymphoma, Burkitt lymphoma, Philadelphia chromosome-negative ( $\mathrm{Ph}-$ ) acute lymphoblastic leukemia (ALL) and also solid tumors for all the group. ${ }^{22}$ A large spectrum of clinical trials continuing for further improvement of this drug efficacy [NCT00495079, NCT00022555, and NCT00516295].

\section{Vinorelbine Tartrate}

Vinorelbine tartrate is a bitartrate salt of alkaloid isolated from the Vinca rosea L. (Apocynaceae) leaves, with antitumor activities. Vinorelbine has antimitotic properties by inhibiting microtubule polymerization and results in apoptosis. A Phase II clinical study using vinorelbine as a single chemotherapy agent $\left(25 \mathrm{mg} / \mathrm{m}^{2}\right.$, weekly for 8 weeks $)$ in metastatic gastroesophageal adenocarcinoma patients show a median OS of 7.8 months but with mild toxicity including myelosuppression, neutropenia, and constipation. Vinorelbine tartrate is approved by US FDA, as brand name Navelbine, in 1994, for the treatment of non-small cell lung cancer, advanced gastroesophageal adenocarcinoma, and

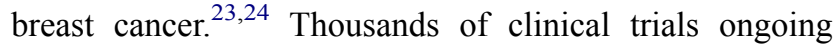
using the vinorelbine as a major chemotherapy agent in patients with various cancer types such as metastatic breast, esophageal squamous cell carcinoma, and lung cancer [NCT00432562, NCT00675597, and NCT01222715].

\section{Vinflunine Ditartrate [Javlor]}

Vinflunine ditartrate is a novel bi-fluorinated derivative of alkaloid vinorelbine extracted from the plant Vinca rosea $\mathrm{L}$. (Apocynaceae), with antitumor activities. Javlor has antiangiogenic, antimicrotubule, and antimitotic activities inducing mitotic cell cycle arrest at the G2/M phase, resulting in apoptotic cancer cell death. Vinflunine ditartrate infused as monotherapy in adult advanced transitional cell carcinoma of the urothelial tract (TCCU) as second-line therapy after failure of the first-line platinum-based regimen. In a multicenter, phase III clinical experiment, 370 patients were randomly allotted the treatment with [vinflunine (VFL) + BSC (best supportive care), n-253], and BSC (n-117). The median OS rate of (VFL + BSC) treatment was 6.9 months, compared to 4.6 months of (BSC) arm. Although nonsignificant OS, PFS (progression-free survival) rate has a significant difference ( $3 \mathrm{~m}$ of VFL compared to $1.5 \mathrm{~m}$ in BSC). This trial recommended a dose of $280-320 \mathrm{mg} / \mathrm{m}^{2}, 20 \mathrm{mn}$ infusion, every 21 days for the subsequent cycles. ${ }^{25}$ Vinflunine was approved by the European Medicines Agency (EMA), in 2009, for the treatment of metastatic and advanced urothelial cancer where platinum-based treatment fails. ${ }^{26}$ Currently, this drug has ongoing clinical trials for the treatment of various cancer types such as hormonerefractory prostate cancer (phase II), relapsed extensive SCLC (phase II), recurrent or metastatic head and neck carcinoma (phase III) [NCT00545766, NCT00284154, and NCT02347332]. 


\section{Fosbretabulin Tromethamine [CA4P]}

Fosbretabulin tromethamine, also known as combretastatin A4 phosphate (CA4P) is a water-soluble disodium salt of a natural phenol derivative, extracted from the plant Combretum caffrum (African bush willow), with potential antitumor properties. This is an antimicrotubule, antiangiogenic, and antimitotic agent. It depolymerizes microtubule assembly, disrupts mitosis, disrupts tumor vasculature, and facilitates apoptosis in the tumor cells. A Phase II clinical trial of CA4P in advanced nonsquamous NSLC patients was conducted with dosing of $60 \mathrm{mg} / \mathrm{m}^{2}$ weekly for every cycle of 21 days. Results show CA4P treated patients have a $50 \%$ overall tumor response rate compared to $32 \%$ of the control group. ${ }^{27} \mathrm{CA} 4 \mathrm{P}$ is ongoing with several clinical trials for the treatment of ovarian, epithelial, fallopian tube, neuroendocrine tumor, and lung cancer [NCT01305213, NCT02132468, and NCT00653939].

\section{Ombrabulin [AVE8062]}

Ombrabulin is a natural phenol derivative of combretastatin A4, extracted from the plant Combretum caffrum (Combretaceae), with potential antitumor properties. Ombrabulin binds to the colchicines binding site, inhibiting tubulin polymerization and inducing mitotic arrest and apoptosis in endothelial cells. In a phase I trial, antineoplastic agent ombrabulin $\left(15.5-35 \mathrm{mg} / \mathrm{m}^{2}\right.$ infusion up to $30 \mathrm{mn}$, the first day of every week for 3 weeks) has shown $1 \mathrm{CR}, 15 \mathrm{PR}$ in advanced solid tumor patients with feasibility up to 3 weeks regimen along with docetaxel. ${ }^{28}$ Ombrabulin has been used in trials studying the treatment of sarcoma, neoplasms, solid tumors,malignant and advanced solid tumors, among others [NCT00699517, NCT01907685, and NCT01263886].

\section{Idronoxil [Phenoxodiol]}

Idronoxil, also known as phenoxodiol, flavonoid derivative of plant Glycin max Linn. (Fabaceae), with potent antineoplastic activities. This drug activates tumor cell apoptosis via activating caspase cascade and disrupting apoptosis inhibitors (XIAP). Idronoxil also induces cell cycle arrest by inhibiting DNA topoisomerase II and preventing the replication of DNA. ${ }^{29}$ In a phase I trial, each metastatic solid tumor patient received phenoxodiol at $5 \mathrm{mg} / \mathrm{kg}$ over $5 \mathrm{mn}$ for 6 weeks of bolus infusion followed by $2 \mathrm{mg} / \mathrm{kg} / \mathrm{hr}$ continuous infusion. This resulted in short half-life $(0.67 \pm 0.53 \mathrm{~h}$ and $3.19 \pm$ $1.93 \mathrm{~h})$ and fast rate of plasma clearance $(2.48 \pm 2.33$
$\mathrm{L} / \mathrm{h}$ and $0.15 \pm 0.08 \mathrm{~L} / \mathrm{h}$,) even with continuous infusion of the drug, leading to rapid steady-state. ${ }^{30}$ Phase I and phase III clinical studies on phenoxodiol as an anticancer drug for solid tumor, prostate cancer, and ovarian cancer treatment suggested that phenoxodiol as a broad spectrum chemo-sensitizer, tumor-specific and multi-pathway apoptosis-inducing drug. ${ }^{30,31}$ This drug has several ongoing clinical trials on patients having fallopian tube cancer and prostate cancer [NCT00382811, NCT00557037, and NCT00382811].

\section{Genistein}

Genistein is a phytoestrogen isoflavone, isolated from the plant Glycin max Linn. (Fabaceae), with antineoplastic, antioxidant properties. Mechanistic intuition of Genistein depicts its potential for inhibition of topoisomerase-II and proteintyrosine kinase activity, leading to cell cycle arrest at the G2/M phase and apoptosis induction, as well as antioxidant, antiangiogenic, and anti-inflammatory properties. ${ }^{10,32}$ Genistein has been used for the treatment of metastatic colorectal cancer (phase I/II), early-stage prostate cancer (phase II), stage IV breast cancer (phase II) under various clinical trials [NCT01985763, NCT01325311, and NCT00244933].

\section{Ingenol Mebutate [PEP 005]}

Ingenol mebutate [PEP 005] is a salt of ingenol, extracted from the plant sap of Euphorbia peplus (Euphorbiaceae), with potent antineoplastic activities. This agent is a protein kinase C (PKC) activator, regulated cell cycle inducing apoptosis in various cancer certain tumor cells, including myeloid leukemia cells, melanoma cells, and basal cell carcinoma cells. Recently, the US FDA approved this drug, in 2012 , for the actinic keratosis topical treatment. ${ }^{33}$ This drug is under various cancer treatment trials of basal cell carcinoma (phase I/II) and non-invasive lentigo melanoma of the face (phase II) [NCT03569345, NCT00108121, and NCT02723721].

\section{Betulinic Acid}

Betulinic acid is a lupane of pentacyclic triterpenoid betulin, extracted from the bark of the plant Betula pubescens (Betulaceae) with anti-inflammatory and antineoplastic activities. It is a DNA topoisomerase inhibitor, induces apoptosis via mitochondrial disruption, activating caspase cascades. $^{30}$ A phase-I trial is ongoing as a topical ointment for the treatment of cutaneous metastatic melanoma [NCT00701987]. 


\section{Maytansine}

Maytansine is a macrocyclic lactam antibiotic extracted from the bark of shrub Maytenus ovatus (Celastraceae) with potent antineoplastic activities. It is an anti-tubulin, antimitotic drug used in combination with an antibody (ADC) called Trastuzumab emtansine. The only maytansinoid-based ADC, approved by the US FDA, in 2013 is trastuzumab for the treatment of HER2-positive metastatic breast cancer. ${ }^{35}$ This drug is under trials to treat various cancer types such as metastatic non-small cell lung cancer (NSCLC) (phase II), advanced breast cancer (phase I/II), and colorectal cancer [NCT02289833, NCT00934856, and NCT01641939].

\section{Sulforaphane}

Sulforaphane is a natural isothiocyanate isolated from crucifer plant Brassica oleracea (Brassicaceae), with potent anticancer effects. It is a secondary plant metabolite having antioxidant, antimitotic, and antiangiogenic properties. It acts through (i) blocking mutagen action; (ii) inhibiting cell cycle and inducing apoptosis clearing tumor cells; (iii) disrupting neoangiogenesis in cancer metastasis. ${ }^{36}$ Currently, this drug is under various clinical trials for the treatment of cancer such as lung cancer (phase II), prostate cancer (phase II), metastatic breast cancer (phase II) [NCT03232138, NCT01228084, and NCT02970682].

\section{Epigallocatechin Gallate [EGCG]}

Epigallocatechin gallate is a polyphenol, flavan and gallate ester, catechin, isolated from the tea plant Camellia sinensis (Theaceae). It acts as an antioxidant, anti-Hsp90, antineoplastic agent, with neuroprotective activities. ${ }^{37}$ This drug is under the clinical trial of various cancer treatments including colorectal cancer (phase I), lung cancer (phase II), and prostate cancer undergoing surgery (phase I) [NCT02891538, NCT02577393, and NCT00459407].

\section{Curcumin}

Curcumin is a polyphenol (beta-diketone), a purified extract of turmeric root obtained from ferulic acid and originally isolated from the Indian plant Curcuma longa (Zingiberaceae). It has antifungal, antibacterial, and antineoplastic activities. It is have been approved by the US FDA (GRN-686) as "Generally Recognized As Safe" (GRAS). ${ }^{34}$ This drug is under clinical trials for the treatment of several cancer types such as breast cancer, pancreatic, and prostate cancer [NCT01917890, NCT01160302, and NCT02554344].

\section{R-(-)-Gossypol Acetic Acid}

R-(-)-Gossypol acetic acid is a polyphenol (gossypol) isolated from the seeds of the plant Gossypium herbaceum (Malvaceae), also a BCL-2 homolog domain 3 mimetic, comprising of R-(-) enantiomer solvate of the gossypol along with acetic acid with potential antitumor activity. R-(-)-Gossypol acetic acid intercalates with antiapoptotic proteins (Bcl-2 and $\mathrm{Bcl}-\mathrm{xL}$ ) for separating proapoptotic proteins (Bid, Bad, and Bim) to enhance apoptosis process through cell cycle arrest at G0/G1 phase, hence restricting tumor cell proliferation. ${ }^{39}$ This drug has tremendous scope to qualify as an anticancer drug and currently under phase I/II clinical trials for the treatment of 78 more cancer types including multiple myeloma, lung cancer, prostate cancer, and solid tumor [NCT00773955, NCT00397293, and NCT00666666].

\section{Beta-Lapachone [ARQ 50I]}

$\beta$-Lapachone is a natural ortho-naphthoquinone and a bark extract from the tree Tabebuia avellanedae (Bignoniaceae), with antineoplastic properties. Beta-lapachone generates high levels of ROS (reactive oxygen species) that induce DNA damage, resulting in cell cycle arrest and apoptosis, upon activation with NQO1 (quinone oxidoreductase-, a flavoprotein). Hence, this drug can be effective in treating tumors overexpressing NQO1. ${ }^{40} \beta$-Lapachone is under various clinical trials for the treatment of carcinoma, pancreatic cancer, solid tumors, head and neck neoplasm, lymphoma, and carcinoma [NCT00524524, NCT00099190, and NCT00358930].

\section{Cryptophycins 52 [LY355703]}

Cryptophycins 52, is a cytotoxin, initially isolated from blue algae called cyanobacteria (Nostoc sp. ATCC 53,789, Nostoc sp. GSV 224) of Nostocaceae family, a potent microtubule inhibitor, with potential antineoplastic properties. Upon treatment it disrupts microtubule, preventing cell cycle and results in apoptosis. Cryptophycins 52, has completed phase-II clinical trials for the treatment of platinumresistant ovarian cancer and advanced non-small cell lung cancer. $^{41,42}$ In a phase II trial, Cryptophycins 52 chemodrug administered at $1.125-1.5 \mathrm{mg} / \mathrm{m}^{2}$ on days 1 and 8 for every 3 weeks, assessed for every 2 cycles in advanced nonsmall cell lung cancer patients. Results show reduced toxicity but unacceptable levels of peripheral neuropathy toxicity observed at $1.5 \mathrm{mg} / \mathrm{m}^{2}$ dose concentration. SD rate of $40 \%$ was evident. This mandate substantial change in dosage protocol for further clinical trials. ${ }^{42}$ 


\section{Lovastatin}

Lovastatin is a natural statin, a delta lactone, a polyketide, a fatty acid ester, a HMG-CoA reductase inhibitor, isolated from oyster mushroom Pleurotus ostreatus (Pleurotaceae) with antitumor properties. This drug is under clinical trial for the treatment of melanoma, breast cancer [NCT00462280, NCT00584012, and NCT00902668].

\section{Kanglaite [Coix Seed Oil]}

Kanglaite is a form of natural oil extracted from the seeds of plant Coix lacryma-jobi (Cramineae) with antineoplastic activity. The therapeutic formulation is an injectable microemulsion of purified coix seed oil. Although the drug mechanism of action is unclear, kanglaite significantly reduces tumor via cell cycle arrest at the G2/M phase, eventually resulting in apoptosis of cancer cells. This drug has been approved in China (1995) for hepatocellular carcinoma and advanced non-small cell lung cancer treatment. $^{43}$ Over 20 years of observation taking millions of patients from multiple countries has shown effective outcomes without side effects. Currently, this drug is under the US FDA approval process. ${ }^{43}$ Kanglaite is under clinical trials for the treatment of pancreatic cancer, non-small cell lung, and cachexia [NCT02553187, NCT03986528, and NCT00733850].

\section{Simvastatin}

Simvastatin is a hydroxymethylglutaryl-CoA reductase inhibitor, extracted from the fungus. Aspergillus terreus (Trichocomaceae), with antineoplastic activities. It lowers tumor proliferation by restricting its growth at the G0/G1 phase of the cell cycle, inducing apoptotic cancer cell death. In a phase-II clinical trial, simvastatin is found to reduce recurrence of the breast cancer through modulation of estrone sulfate concentrations by reducing its chemoresistance activity. ${ }^{44}$ Breast cancer patients of stage 0-III administered with oral simvastatin (40 mg) for 24-28 weeks. Results show a significant reduction in lipid profile and cancer marker high-sensitivity C-reactive protein (hsCRP) by limiting estrone sulfate concentrations. This clinical study suggests the feasibility of Simvastatin in chemoresistant breast cancer treatment. Simvastatin drug is currently used in combination with other drugs undergoing clinical trials for the treatment of metastatic breast cancer, adenocarcinoma of the rectum, stomach cancer, pancreatic cancer, and prostate carcinoma [NCT03324425, NCT00334542, and NCT00944463].

\section{Paclitaxel [Taxol]}

Paclitaxel, a microtubule inhibitor with a tetracyclic diterpenoid structure, extracted from the tree Taxus brevifolia (Taxaceae) bark, is currently being used for the therapy of breast, ovarian, pancreatic, and lung cancer. Paclitaxel arrest cells growth and division by blocking the cell cycle $\mathrm{G} 2 / \mathrm{M}$ phase inducing apoptosis in cancer cells. Armstrong et al demonstrated that paclitaxel when administered intravenously with intraperitoneal cisplatin significantly improved overall survival rate and progression-free survival in patients with stage-III ovarian cancer. $^{45}$ Paclitaxel, although associated with mild asymptomatic liver transaminase elevation, however, clinical liver failure has not been documented. It received FDA approval for the treatment of refractory breast cancer back in 1992.

\section{Taxoprexin [DHA-Paclitaxel]}

DHA-Paclitaxel is a combination of a natural fatty acid (DHA) and paclitaxel, with antineoplastic activities. It is a type of mitotic inhibitor, has been studied as first-line treatment in patients with stage IIIB/IV non-small-cell lung cancer. As a single-agent, the combination has little activity in patients with advanced non-small-cell lung cancer, with less than half of patients achieving either disease stability or responding partially. However, the survival advantage achieved is comparable with the more toxic standard platinum-based combination chemotherapy. Myelosuppression is a major dose-related toxicity of Taxoprexin. ${ }^{46}$ DHA-Paclitaxel is currently ongoing clinical trials for the treatment of non-small cell lung cancer, metastatic melanoma [NCT00244816, NCT00249262, and NCT00243867].

\section{Larotaxel [XRP988I]}

Larotaxel, a semi-synthetic taxane, with good blood-brain barrier (BBB) permeability. It prevents microtubule depolymerization by binding to and stabilizing microtubule assembly, leading to cell cycle arrest at the G2/M phase and apoptosis. Due to less affinity for P-glycoprotein, this agent may be useful for treating multi-drug resistant tumors. In advanced/metastatic NSCLC patients, larotaxel in combination with carboplatin has shown promising efficacy and lower neutropenia toxicity. ${ }^{47}$ Larotaxel has been used in clinical trials for the treatment of breast neoplasms and pancreatic adenocarcinoma, among others [NCT00387907, NCT00417209, and NCT00625664]. 


\section{Ortataxel [IDN-5 I09/BAY 59-8862]}

Ortataxel is a second-generation derivative of taxane, isolated from tree Taxus baccata L. (Taxaceae) with potential antitumor activity. It inhibits cell proliferation by binding to microtubule arresting cell cycle phase arrest. Structurally, a semi-synthetic taxane and functionally, a microtubule stabilizer, it interacts and interferes with the microtubule assembly/disassembly, thereby leading to arrest of cell cycle and tumor proliferation. Exhibiting poor affinity for P-glycoprotein, multidrug resistance protein (MRP-1) and breast cancer resistance protein (BCRP) mediated efflux, it holds the potential for the treatment of multidrug resistance (MDR) tumors expressing these proteins. ${ }^{48}$ Ortataxel has been studied in clinical trials for the treatment of glioblastoma, lymphoma, and neoplasia of the kidney and lungs [NCT01989884, NCT00054314, and NCT00039169].

\section{MAC 32I [Milataxel]}

Milataxel, orally bioavailable taxane, acting as a microtubule stabilizer in conjunction with its active metabolite M-10, it inhibits the depolymerization of microtubules and arrests the cell cycle in the G2/M phase, leading to its antiproliferative effect on neoplastic cells. Due to less affinity for multidrug-resistant (MDR) membrane-associated P-glycoprotein, this agent may be useful for treating MDR tumors. A phase II study of milataxel in previously treated patients with advanced colorectal cancer did not show any favorable clinical outcome. However, a clear risk of line threatening neutropenic sepsis and diarrhea were noted in the subjects receiving the molecule, demanding closer surveillance. ${ }^{49}$ Milataxel is under clinical trials for the treatment of mesothelioma, lung cancer, and colorectal cancer [NCT00685204, NCT00063219, and NCT00063427].

\section{UNII-A2VM2V569A [TPI-287]}

TPI 287, a structurally modified synthetic taxane with better central nervous system (CNS) penetration and with the ability to evade potential multidrug resistance efflux pump mechanisms, with antineoplastic activities. The drug is currently undergoing a phase- 1 trial for the treatment of metastatic melanoma, which aims to establish the maximum tolerable dose of the combination. ${ }^{50}$ Another Phase-1 study of 18 patients with refractory/recurrent neuroblastoma or medulloblastoma in combination with temozolomide showed good toleration among the pediatric population at a dose of $125 \mathrm{mg} / \mathrm{m}^{2}$ on days 1,8 , and 15 of a 28 -day cycle. ${ }^{51}$

\section{BMS-275, I83 [Oral Taxane]}

BMS-275,183 is an oral taxane, with antineoplastic activities. It has been used in trials studying the treatment of non-small cell lung cancer (NSCLC). A Phase I-II doseranging study of BMS-275,183 in combination with pemetrexed (Alimta) in patients with recurrent NSCLC is underway. The trial aims to study the safety and efficacy of this combination treatment [NCT00103831].

\section{DJ 927[Tesetaxel]}

DJ 927 is a semi-synthetic oral taxane with antimitotic, anti-VEGF, and antineoplastic properties. It prevents microtubule depolymerization by binding to and stabilizing microtubule assembly, leading to cell cycle arrest and tumor cell proliferation. Due to less affinity for P-glycoprotein, this agent may be useful for treating multi-drug resistant tumors. ${ }^{52}$ Tesetaxel has been used in trials for the treatment of gastric carcinoma, metastatic melanoma, prostate cancer, and advanced solid tumors, among others [NCT01064713, NCT00077077, and NCT01573468].

\section{Cabazitaxel [Jevtana]}

Cabazitaxel, a Microtubule inhibitor and a semi-synthetically derived molecule from natural taxoid 10-deacetylbaccatin III, is currently used for castration-resistant metastatic prostate cancer which has failed treatment with docetaxel. ${ }^{53}$ It prevents microtubule depolymerization by binding to and stabilizing microtubule assembly, leading to cell cycle arrest and tumor cell proliferation. In 2009, the US FDA approved Jevtana for prostate cancer treatment only in combination with prednisone to be administered intravenously. ${ }^{53}$ Due to less affinity for P-glycoprotein, this agent may be useful for treating multi-drug resistant tumors. Currently, this drug is under clinical phase trials for the treatment of malignant solid tumor, malignant nervous system neoplasm, NSCLC, metastatic prostate cancer [NCT01751308, NCT01438307, and NCT01308580].

\section{Elliptinium Acetate [Celiptium]}

Celiptium is an alkaloid derivative of ellipticine, isolated from plant Bleekeria vitensis (Apocynaceae), its acetate salt has anti-neoplastic properties. A topoisomerase II inhibitor and intercalating agent, it induces DNA breakages, thereby inhibiting transcription and translation of proteins. It is presently undergoing Phase II study for 
salvage treatment (weekly dosage) of advanced breast cancer. The 3-week schedule found to be less toxic compared to the weekly regimen. ${ }^{54}$

\section{Omacetaxine Mepesuccinate [Synribo]}

Omacetaxine is a semisynthetic cephalotaxine alkaloid ester isolated from the plant Cephalotaxus harringtonia var. drupacea (Cephalotaxaceae) leaves; that acts as a protein translation inhibitor and is used to treated chronic myeloid leukemia that is resistant to tyrosine kinase receptor antagonists. Most recently, this drug is approved by the US FDA, in 2012, for patients of tyrosine kinase inhibitors resistant accelerated/ chronic phase $\mathrm{CM}^{55}$ Subcutaneous omacetaxine mepesuccinate accelerates tumor cell death leading to tumor cell clearance. Omacetaxine Mepesuccinate is currently under clinical trial to treat various cancer types such as leukemia and solid tumors [NCT00006364, NCT00462943, and NCT00675350].

\section{Nanotechnology in Cancer Diagnosis and Target-Specific Treatment as Phyto- Nanoformulations}

Nanomedicine invention and development have exceedingly advanced during the past few years. Nanoparticles conjugated plant extract-anticancer drugs have significantly superior potency compared to its conventional therapy as it can cross bio-membrane barriers spontaneously owing to its nanosize and surface reactivity to achieve required concentrations in tumor with slower elimination, without harming surrounding normal tissues from drug toxicity. Nanodrug constructs also facilitate the enhanced localization of tumors as contrast agents as well as efficient delivery of different anticancer therapeutics under control of external (UV-rays, X-ray, laser ray) or internal ( $\mathrm{pH}$, temperature, redox) stimuli for surgically impervious malignant tumors. ${ }^{56-59}$ Numerous plant-based anticancer nanoformulations have been approved by the FDA, and dozens are in clinical trials. Most recently approved nanomedicine core materials are based on previously approved conventional drugs.

Active and passive targeting using nanodrugs via inducing cell cycle arrest and apoptosis can provide a unique non-invasive approach to counter malignant tumors minimizing systemic toxicity. ${ }^{3}$ Active targeting is a superior and more precise way of cancer-targeting usually relies on the receptor-ligand reciprocity, in which nanodrug acts as a ligand that binds to the definite receptors on the tumor cell surface, activating various signaling cascade, progressing apoptotic cancer cell death as depicted in Figure 4. The use of nanocarriers such as liposomes, micelle, dendrimers, nanodispersions, polymeric nanoparticles, nanotubes, nanorods, and metallic/non-metallic nanoparticles has ineluctably impacted cancer pharmacology. ${ }^{59}$ Phytomolecules conjugated anti-neoplastic drugs in nanosize diffuse through the cell membrane escaping immune defense mechanism is known as passive targeting as depicted in Figure 4. Phyto-nanocomposite circulates through the cytoplasm, diffuse into intracellular organelles inducing oxidative stress and loss of mitochondrial membrane potential, progressing apoptosis in cancer cells. As aforementioned in Figure 4, phyto-nanocomposite clears tumor through active and passive targeting inducing oxidative stress, activating various signaling pathways, caspase activation in a controlled and target-specific manner. ROS above the threshold level causes oxidative stress, trigger apoptotic signals through modulating multiple signaling pathways, including the MAPK/JNK (mitogen-activated protein kinase/c-Jun N-terminal kinase), P38/MAPK pathway, MAPK/ERK (extracellular-signal-regulated kinase), SAPK (stress-activated protein kinases)/JNK, TRAIL (Tumour necrosis factor (TNF)-related apoptosisinducing ligand) mediated pathway, PI3K/AKT (phosphoinositide-3-kinase/protein kinase B), P53 mediated apoptotic pathways, Caspase mediated, NFKB (nuclear factor $\kappa B)$, signaling pathways. ${ }^{8}$ Nanoparticles-based anti-neoplastic agents having phytomolecules have revolutionized conventional cancer therapy greatly advancing clinical practice. The present section followed by detailed coverage of the approved formulations in clinical use along with an insight of various phyto-nanodrug vehicle nanomedicines under clinical trials to clinical use in cancer therapeutics mentioned in Table 3.

\section{Paclitaxel Albumin-Stabilized Nanoparticle Formulation [Abraxane ${ }^{\circledR}$ ]}

Abraxane is a Cremophor toxin-free, nanoparticle composite stabilized with human serum albumin using natural taxane paclitaxel as a core drug. This nano-formulation permits the administration of increased doses ( $4-5$ folds) of paclitaxel as toxic cremophor is absent, along with reduced infusion time, eliminating premedication. ${ }^{60}$ This drug is used alone or in conjugation to treat pancreatic cancer, metastatic breast cancer, lung cancer, and bladder cancer like many other cancer types. The new nano- 


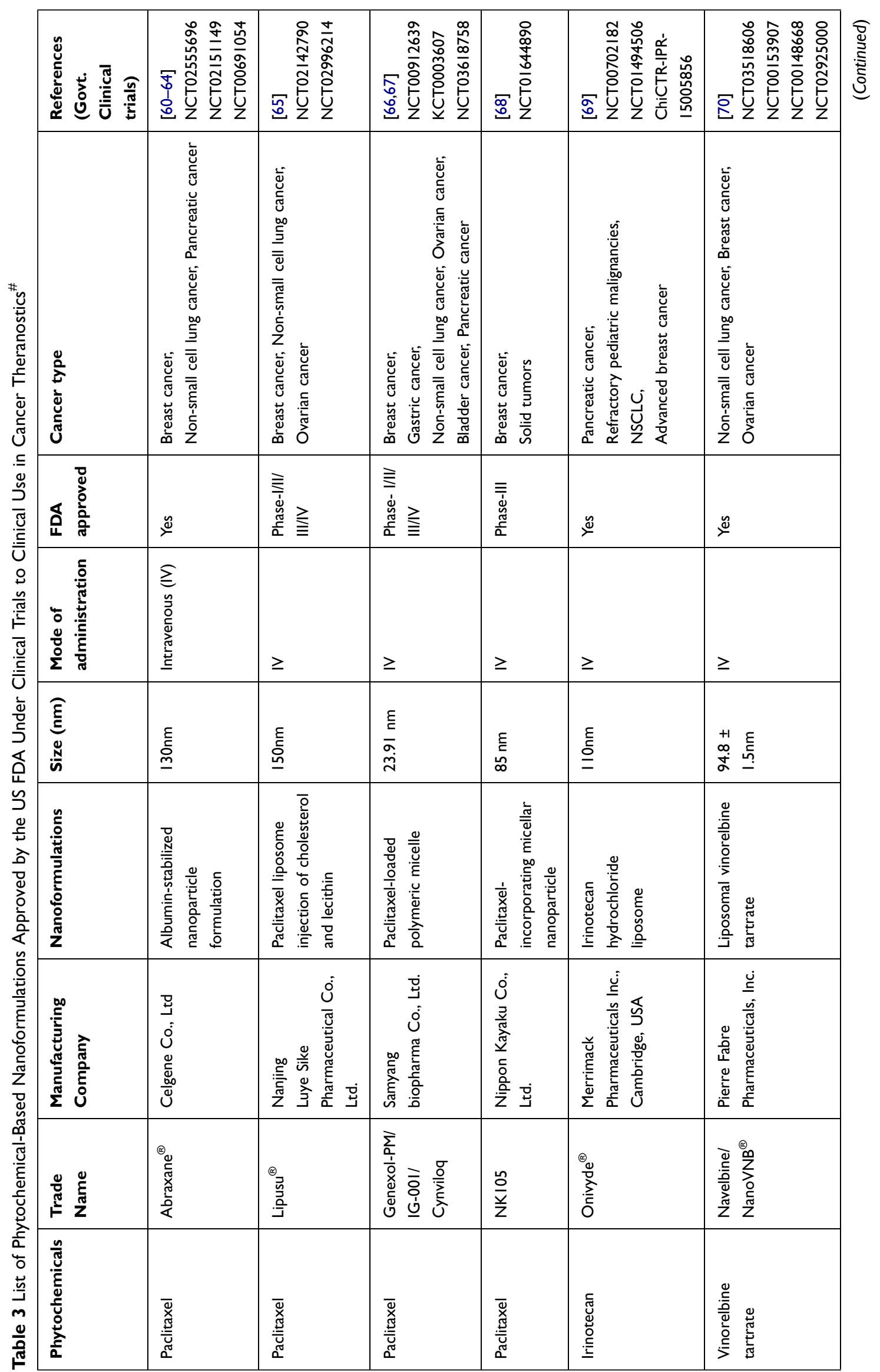




\begin{tabular}{|c|c|c|c|c|c|c|c|c|}
\hline 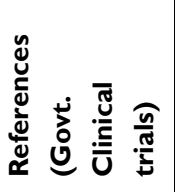 & 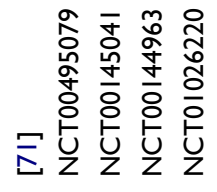 & 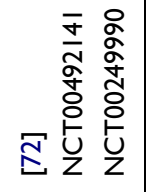 & 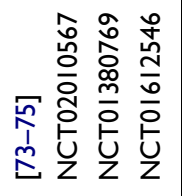 & 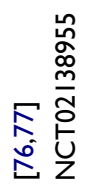 & 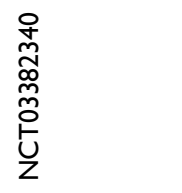 & 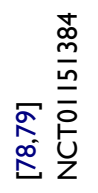 & 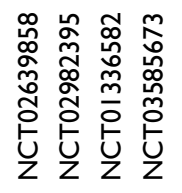 & 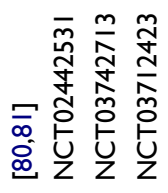 \\
\hline 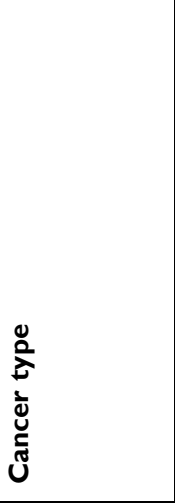 & 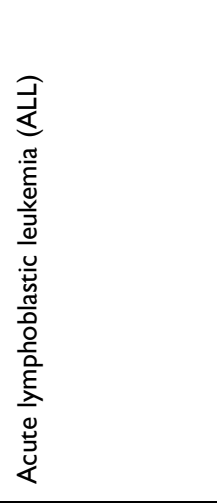 & 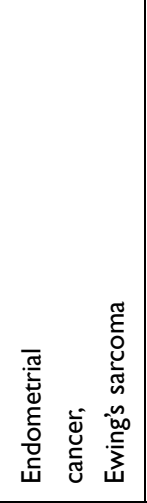 & 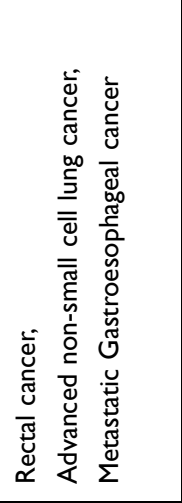 & 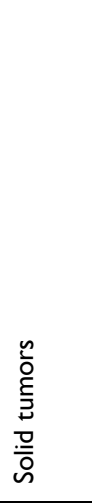 & 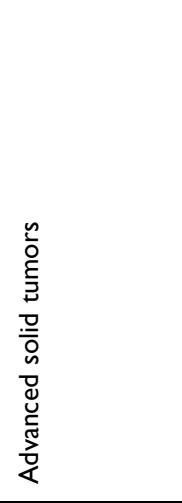 & 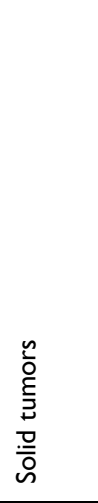 & 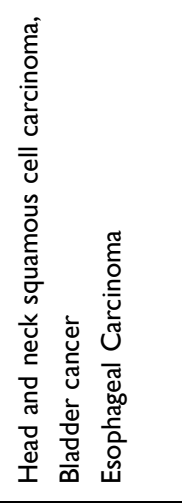 & 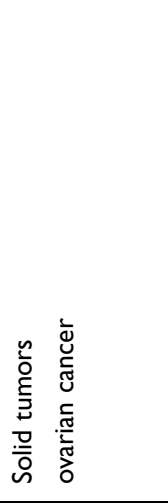 \\
\hline 造高 & 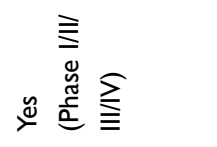 & 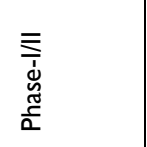 & 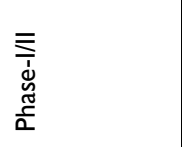 & 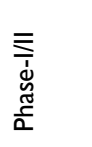 & 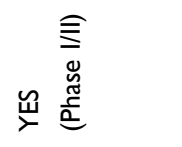 & 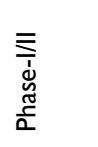 & 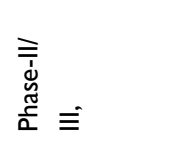 & 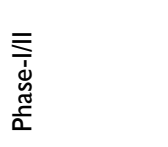 \\
\hline 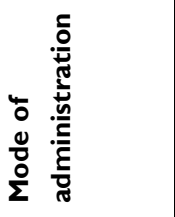 & $\geq$ & $\geq$ & $\geq$ & $\geq$ & $\geq$ & $\geq$ & $\geq$ & $\geq$ \\
\hline 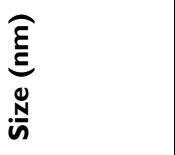 & $\begin{array}{l}\underline{E} \\
\underline{\underline{0}} \\
\underline{\underline{0}}\end{array}$ & $\begin{array}{l}\varepsilon \\
\underline{\Xi} \\
\varrho\end{array}$ & $\begin{array}{l}\frac{\varepsilon}{c} \\
\frac{o}{v} \\
v\end{array}$ & $\begin{array}{l}\underline{E} \\
\underline{\Sigma} \\
\underline{I}\end{array}$ & $\begin{array}{l}\varepsilon \\
\varepsilon \\
o \\
o \\
1 \\
b \\
o \\
m\end{array}$ & $\begin{array}{l}\underline{E} \\
\underline{\Xi} \\
\underline{\Xi}\end{array}$ & 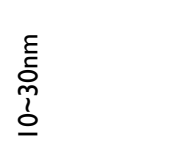 & 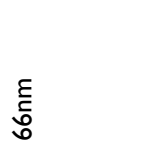 \\
\hline 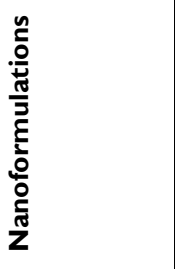 & 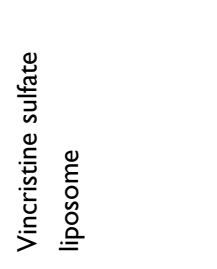 & 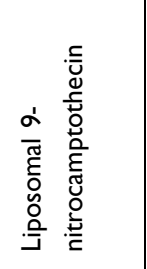 & 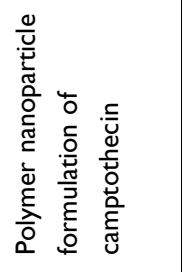 & 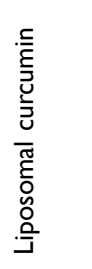 & 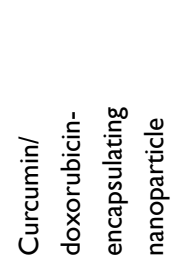 & 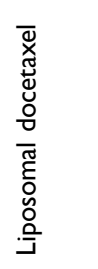 & 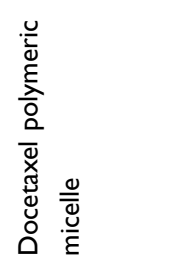 & 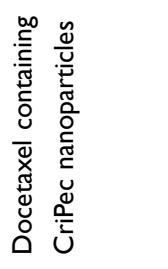 \\
\hline 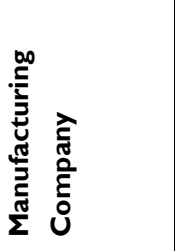 & 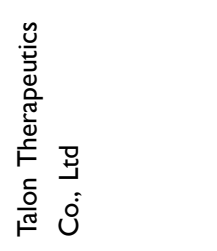 & 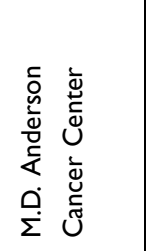 & 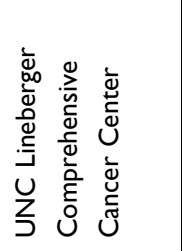 & 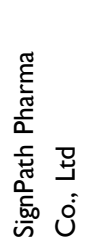 & 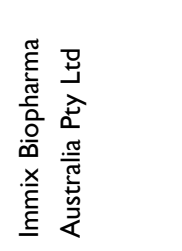 & 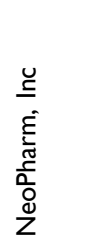 & 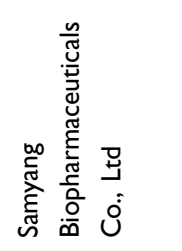 & 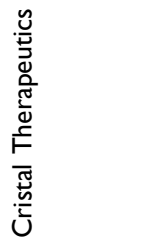 \\
\hline 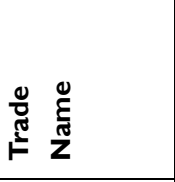 & 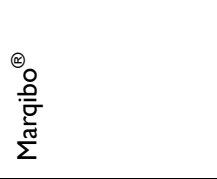 & $\begin{array}{l}u \\
Z_{1} \\
\text { S }\end{array}$ & 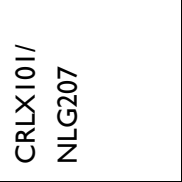 & 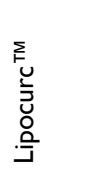 & $\frac{\underline{0}}{\underline{\bar{x}}}$ & 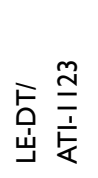 & 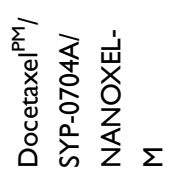 & 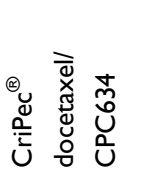 \\
\hline 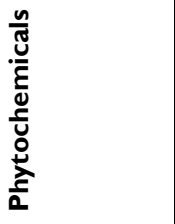 & 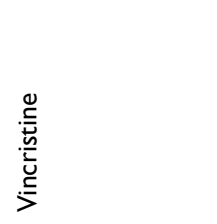 & 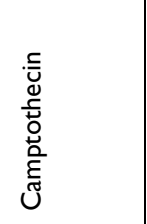 & 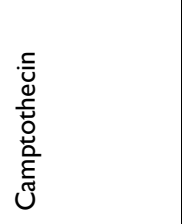 & 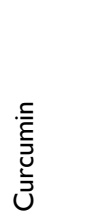 & 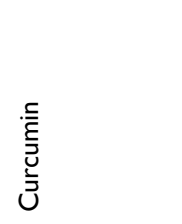 & 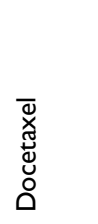 & 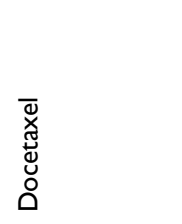 & 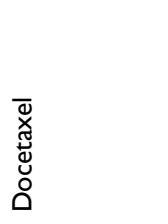 \\
\hline
\end{tabular}




\begin{tabular}{|c|c|c|}
\hline 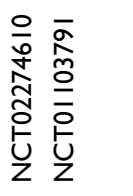 & 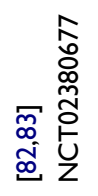 & 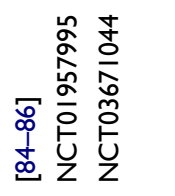 \\
\hline 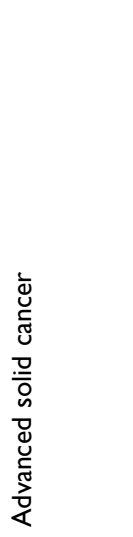 & 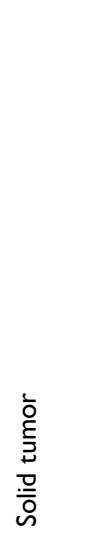 & 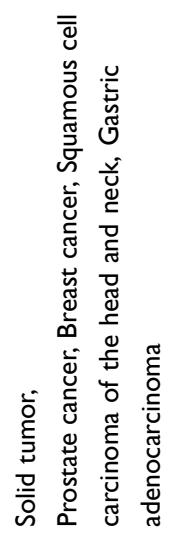 \\
\hline 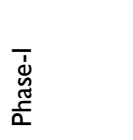 & 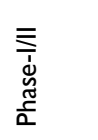 & 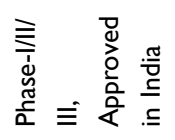 \\
\hline$\geq$ & $\geq$ & $\geq$ \\
\hline $\begin{array}{l}\varepsilon \\
\bar{\emptyset} \\
\frac{\delta}{b} \\
\underline{0}\end{array}$ & 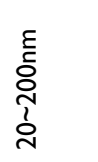 & $\begin{array}{l}\frac{\varepsilon}{E} \\
\frac{o}{v}\end{array}$ \\
\hline 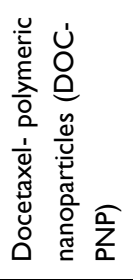 & 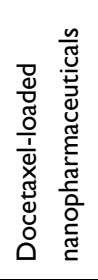 & 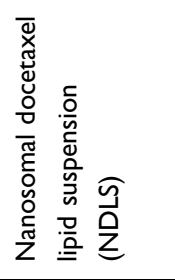 \\
\hline 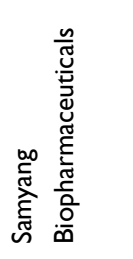 & 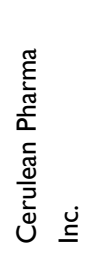 & 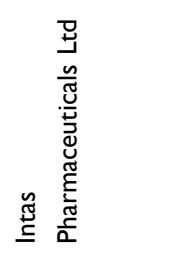 \\
\hline 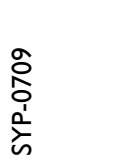 & 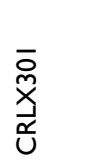 & 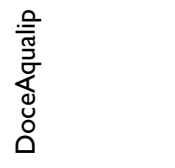 \\
\hline 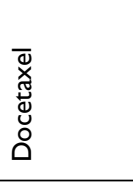 & 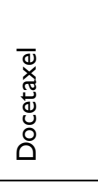 & 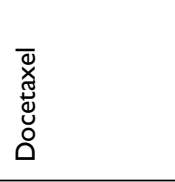 \\
\hline
\end{tabular}

formulation binds to the albumin receptor of the endothelial cells and the other proteins overexpressed in cancer cells to transfer drugs into the cytoplasm. Nano-size cancer drugs achieved higher intratumoral accumulation and better bioavailability compared to its conventional paclitaxel alone improving the cancer therapeutic index in various cancer types. ${ }^{60}$

\section{Breast Cancer Treatment}

Breast cancer leads to be the topmost prevalent cancer in women among other cancer types worldwide. Among breast cancer drugs, paclitaxel found to be the most effective, in contrast to possessing severe toxic side effects. To overcome such strong toxic effects, nano-formulation like nab-paclitaxel has reached pivotal clinical trials and approved to be used for breast cancer treatment. Gradishar et al in 2005, administered intravenously nabpaclitaxel $\left(260 \mathrm{mg} / \mathrm{m}^{2}\right)$ with no premedication to 299 patients and with conventional paclitaxel $\left(175 \mathrm{mg} / \mathrm{m}^{2}\right)$ including premedication to other groups of 225 patients at the three-week schedule. The results demonstrated that nano-formulation has improved response over conventional one with lower neutropenia, low toxicity profile, and increased survival advantage. ${ }^{60}$ Consistently, in 2012, an updated study has been published by Gradishar et al which demonstrated that nab-paclitaxel $\left(150 \mathrm{mg} / \mathrm{m}^{2}\right)$ impressively prolonged overall survival rate compared to nab-paclitaxel $\left(100 / 300 \mathrm{mg} / \mathrm{m}^{2}\right)$ and docetaxel $(100 \mathrm{mg} /$ $\mathrm{m}^{2}$ ) when administered to 302 patients with metastatic breast cancer. Altogether nab-paclitaxel reduced fatigue, and febrile neutropenia like severe side effects, proving it to be the most clinically efficacious anti-neoplastic drug for patients with metastatic breast cancer. ${ }^{60,61}$

\section{Pancreatic Cancer Treatment}

Pancreatic cancer is one of the biggest fatal malignancies and aggressive, most prevalent in middle-aged men. It occupies the first place as asymptomatic cancers, predominantly pancreatic adenocarcinomas. Nano-formulation of Nab-paclitaxel and gemcitabine combinatorial drug becomes a standard first-line therapy in metastatic pancreatic adenocarcinomas. A case study by Von Hoff et al in 2013, suggested that in a phase-III trial, nab-paclitaxel plus gemcitabine significantly increased the overall survival rate of metastatic pancreatic adenocarcinomas patient $(n=431)$ with improved safety and lesser side effects after getting a substantial positive response of nab-paclitaxel in phase-I/II clinical trial. ${ }^{62}$ Also, Petrillo et al demonstrated 
that nab-paclitaxel plus gemcitabine is a good choice for geriatric populations as daily clinical practice in metastatic pancreatic adenocarcinoma treatment. ${ }^{63}$

\section{Lung Cancer Treatment}

Lung cancer such as non-small cell lung cancer (NSCLC) is the topmost prevalent cancer type among men. NSCLC is with high risk for clinical chemotherapy regime trials because of its recurrence. A report by Asahina et al in 2019, demonstrated that in a phase-III trial, the overall response rate (ORR) reached to $66.7 \%$ to meet the primary endpoint, median progression-free survival (PFS) increased to 8.2 months, and overall survival (OS) improved to 16.8 months with acceptable toxic effects, when NSCLC patients treated with $100 \mathrm{mg} / \mathrm{m}^{2}$ nab-paclitaxel weekly and carboplatin once every 3 weeks continued for 3-4 cycles. $^{64}$

\section{Paclitaxel Liposome [Lipusu ${ }^{\circledR}$ ]}

Liposome-encapsulated nano-formulation of paclitaxel developed in 2003, which exhibits higher potency of increased solubility, lower cytotoxicity, slow elimination, high tissue concentration, and better pharmacokinetics as compared to paclitaxel alone. Liposomal paclitaxel is cremophor EL free which has severe toxic effects like anaphylaxis. A report by $\mathrm{Xu}$ et al demonstrated that liposomal paclitaxel has a better performance compared to paclitaxel alone when infused the same dose of $135 \mathrm{mg} / \mathrm{m}^{2}$ up to 4 cycles (for $>3 \mathrm{~h}$ on the first day of each cycle comprising of 21days) in patients with metastatic gastric cancer. Cremophor EL free Lipusu and paclitaxel alone have nearly the same response rate $(47 \%$ and $46 \%)$ but liposomal formulation has significantly lower toxic effects like vomiting, nausea and hypersensitivity reactions, as it does not need pre-medications of antihistamines like the conventional one. ${ }^{65}$

\section{Paclitaxel-Loaded Polymeric Micelle [Genexol-PM ${ }^{\circledR}$ ]}

Paclitaxel-loaded polymeric micelle is an $\mathrm{mPEG}$ (monomethoxy polyethylene glycol)-PDLLA (D/L polylactic acid) solubilizer based nanoparticle-polymeric micellar formulation of paclitaxel (Genexol PM) with antineoplastic properties. Paclitaxel binds with polyethylene glycol (PEG) covalently forming a micellar structure having outer PEG shells (hydrophilic) encapsulating the paclitaxel (hydrophobic). This nanodrug is cancer tissue targeted, $\mathrm{pH}$-responsive, and stays stable for a long time in the bloodstream. Upon low $\mathrm{pH}$ stimuli in tumor tissue this drug is released slowly into the tumor microenvironment, accumulates in higher doses with less toxicity to the normal cells. This nano-micellar formulation has improved pharmacokinetics, high solubility, reduced hypersensitivity, superior efficacy, and low toxicity. A report by Lee et al in 2018 demonstrated that micellar Genexol-PM $\left(260 \mathrm{mg} / \mathrm{m}^{2}\right)$ with carboplatin every 3 weeks for 6 cycles has given to the epithelial ovarian cancer patients in a phase-II trial, shown ORR of $88.0 \%$ with manageable toxicity of neutropenia and peripheral neuropathy. ${ }^{66}$ In 2017, Park et al group has reported that Genexol-PM $\left(246.8 \pm 21.3 \mathrm{mg} / \mathrm{m}^{2}\right)$, over 24.5 months of median follow-up show better ORR of $39.1 \%$ and improved toxicity toleration in a phase-III trial of 212 metastatic breast cancer patients in comparison to standard paclitaxel (Genexol) when given intravenously for every 3 weeks. ${ }^{67}$

Paclitaxel-Incorporating Micellar Nanoparticles [NK I05]

A Paclitaxel-incorporating micellar nanoparticle (NK105) is a novel radiosensitizing PEG-polyaspartate micellar nanoparticle formulation encapsulating paclitaxel with antineoplastic effect. Recently in 2019, a report by Fujiwara et al demonstrated in a phase-III open-label clinical trial that paclitaxel nano-formulation NK105 has better safety profile when treated for a 28-day cycle with significant decrease in peripheral sensory neuropathy (PSN) toxicity compared to conventional paclitaxel alone in metastatic/recurrent breast cancer patients. Further, they found NK105 $\left(65 \mathrm{mg} / \mathrm{m}^{2}\right)$ response rate is similar to paclitaxel $\left(80 \mathrm{mg} / \mathrm{m}^{2}\right)$ with better antitumor activity and less non-hematological toxicity in patients with solid tumors. ${ }^{68}$

\section{Irinotecan Hydrochloride Liposome [ONIVYDE ${ }^{\circledR}$ ]}

Pancreatic cancer is among the deadliest cancer types demanding effective therapy globally. Onivyde is an irinotecan phytomolecules conjugating liposomal nanoformulations. Drug irinotecan liposome injection approved for second-line treatment only in combination with 5-FU and LV after first-line treatment with gemcitabine. Irinotecan HCL liposome injection is encapsulated within a lipid bilayer liposome and upon activation by carboxylesterases reaction, converted to active $\mathrm{SN}-38$ metabolite. This topoisomerase-1 inhibitor drug reversibly binds to the topoisomerase-1-DNA complex, causing DNA damage, cell cycle arrest leading to cell death. Wang-Gillam et al, in 2019, reported NAPOLI-1 study results which are a phase-III clinical trial including 417 patients from over 100 locations worldwide demonstrated Onivyde had better 
tumor accumulation in the cytoplasm and improved overall survival rate to 6.1 months in advanced metastatic pancreatic cancer patients. ${ }^{69}$ However, high cytotoxicity of the Onivyde drug has generated concerns about its safety.

\section{Liposomal Vinorelbine Tartrate [Navelbine/NanoVNB ${ }^{\circledR}$ ]} NanoVNB ${ }^{\circledR}$ contains PEGylated nano-liposomal vinorelbine (2 $\mathrm{mg} / \mathrm{mL}$ ), N-(methoxypolyethyleneglycolcarbamyl2000)1,2-distearoyl-sn-glycero-3phosphoethanolamine $(0.23 \mathrm{mg} /$ $\mathrm{mL})$, histidine, distearoyl phosphatidylcholine $(4.45 \mathrm{mg} / \mathrm{mL})$, cholesterol $(1.45 \mathrm{mg} / \mathrm{mL})$ and sucrose. This nano-drug has selective and superior tumor penetration efficacy including slow-release, longer stability, low toxicity, ten times higher plasma concentration $\left(\mathrm{C}_{\max }\right)$, low plasma clearance $(\mathrm{CL})$, superior half-life, and 1500 times higher AUC (area under the curve) compared to the free vinorelbine. A research report by Yang et al demonstrated that liposomal vinorelbine $\left(\mathrm{NanoVNB}^{\circledR}\right.$ ) infused at $2.2-23 \mathrm{mg} / \mathrm{m}^{2}$ dose range once for every 14 days, show low plasma clearance, better pharmacokinetics with low toxic effects including low skin rash without grade 3-4 hematological toxicity, in patients suffering from refractory advanced solid tumors such as nasopharyngeal cancer, angiosarcoma, head and neck cancer, breast cancer, lung cancer, etc. Skin rash occurred at higher dose concentrations $(23.0 \mathrm{mg} / \mathrm{m} 2)$, recommending a dose of $18.5 \mathrm{mg} / \mathrm{m} 2$ every 3 weeks for phase II clinical trials. ${ }^{70}$

\section{Vincristine Sulfate Liposome [Marqibo ${ }^{\circledR}$ ]}

Liposomal nano-formulation of vincristine sulfate (VSLI), composed of sphingosomal/cholesterol as solvent possesses curative anticancer properties and better pharmacokinetics compared to conventional vincristine alone. This drug accumulates passively into the tumor tissue and releases slowly the core drug into the tumor microenvironment, proven to have a better overall response rate. Liposomal formulation along with sphingomyelin reduces its toxic effect considerably; further, longer circulation time improves its therapeutic index. Based on these properties VSLI is prescribed for the treatment of clinically advanced Philadelphia chromosome-negative acute lymphoblastic leukemia (ALL). Recently this nano-formulation of vincristine phytomolecules is under clinical trials for the treatment of several other cancer types, such as Hodgkin lymphoma, malignant melanoma, sarcoma, neuroblastoma. ${ }^{71}$

\section{Liposomal 9-Nitrocamptothecin [L9-NC]}

Aerosolized L-9-nitro-20(S)-camptothecin (L9-NC) is a liposomal nano-formulation of plant alkaloid camptothecin derivative with potential anticancer effects. When used as an aerosol with a nebulizer, the advantages of this drug are readily systemic absorption with less toxicity profile and efficient anticancer activity through cell cycle arrest and apoptosis, as proven by Phase-I/II study in advanced pulmonary malignancies patients. ${ }^{72}$ L9-NC is currently under clinical trials for various cancer therapies such as endometrial cancer, Ewing's sarcoma, and lung cancer (Table 3).

\section{Cyclodextrin-Based Polymer-Camptothecin Nanoparticle [CRLXI0I/NLG207]}

Cyclodextrin-based polymer-camptothecin nanoparticle formulation has potent anticancer properties via cell cycle arrest and cell death. Preferentially this nano-formulations camptothecin accumulated in the target cancer tissues with less toxicity to the normal cells. Nanocamptothecin has a superior half-life of $24 \mathrm{hrs}$ compared to the $2 \mathrm{hrs}$ of conventional drugs which makes it enable for prolonged sustained release of drugs to the cancer site. ${ }^{73}$ Moreover, multiple phase-I/II trials for nano-camptothecin have proven its efficacy as cancer therapeutics. Recent reports demonstrated in a phase-II trial that nanocamptothecin drug conjugate has a better toxicity profile in locally advanced rectal cancer and gastroesophageal cancer patients. ${ }^{74,75}$

\section{Curcumin Liposome [Lipocurc ${ }^{\mathrm{TM}}$ ]}

Liposomal nano-formulation of phyto-compounds such as curcumin polyphenol containing DMPC (14:0-1, 2-dimyristoyl-sn-glycero-3-phosphocholine) and DMPG (14:0-1, 2-dimyristoyl-sn-glycero-3-phosphorylglycerol), possess potential anticancer effects. When infused intravenously, the liposomal carrier increased curcumin plasma levels significantly in a dose-dependent manner in cancer patients. Moreover, upon dose withdrawal, drug clearance rate and the half-life is also shorter than healthy individuals. ${ }^{76}$ In another phase-I clinical study on metastatic tumor patients, liposomal curcumin formulation $\left(300 \mathrm{mg} / \mathrm{m}^{2}\right.$, over $6 \mathrm{~h}$, for 8 weeks) has shown stable plasma concentration with a significant but temporary reduction in tumor markers such as PSA, CEA, CA 19-9. Additionally, liposomal curcumin has sphingosine kinase inhibitor activity, that warrants the use of liposomal curcumin monotherapy or in combination can reduce the recurrence of cancer and suitable for further clinical trials. ${ }^{77}$ Altogether, these reports suggest that lipocurcumin is a safe drug and upon pretreated, as intravenous administration produces ceramide, which reduces cancer markers significantly via cell cycle 
arrest and apoptosis and has a better toxicity profile along with sustained drug release efficacy compared to curcumin alone.

\section{Curcumin/Doxorubicin-Encapsulating Nanoparticle [IMX-} II0]

The phytomolecule-nanoparticle-conjugation formulation comprises of curcumin (Stat3/pan-kinase/NF-kB inhibitor) and a low amount of doxorubicin sheathed in nano-delivery conformity for enhanced tumor infiltration is an apoptosis inducer. To expand its phase $\mathrm{Ib} / \mathrm{IIa}$ clinical trial from Australia to the US, six cohorts have shown no drug-related severe toxicity upon drug augmentation with a potent inhibitory effect against cancer resistance. If needed, this nano-drug can be tuned in such a way that it could be bound to multiple moiety targets, releasing enhanced drug loads in cancer sites or other preferred cell communities. This nano-drug has been approved in July 2019 for the treatment of refractory solid tumors encased with superior efficacy from the perspective of low cardiac toxicity compared to older prescribed formulations (Table 3).

\section{Liposomal-Encapsulated Docetaxel [LE-DT]}

Liposomal nano-formulation of docetaxel (ATI-1123/LEDT) is used for the treatment of various cancer types. This liposomal nano-docetaxel formulation is less toxic, allowing the larger dose administration, enhanced drug solubility, reduces drug degradability, slow drug release/clearance, reducing side-effects and toxicity, thereby improving the overall anticancer efficacy against docetaxel alone. Liposomes are also effective to bring under control multidrug resistance (MDR) specifically mediated by P-glycoprotein (P-gp) and related MDR proteins. ${ }^{78}$ A phase-I study of advanced solid tumor malignancy conducted by Mahalingam et al demonstrated that a liposomal encapsulated docetaxel exhibited favorable pharmacokinetics and stable disease response in $75 \%$ of patients. The maximally tolerated dose suggested being $90 \mathrm{mg} / \mathrm{m}^{2}$ over $1 \mathrm{~h}$ for every 3 weeks when administered intravenously. ${ }^{79}$ In another report by Deeken et al, a new nano-sized stable liposome encased with docetaxel using oppositely charged lipid and the drug had been administered on a dose ranging from $50-132 \mathrm{mg} / \mathrm{m}^{2}$ for 1-30 cycles on every 3 weeks to solid tumor patients. In this clinical trial, the nano-formulations of the drug found to be safe without significant toxicity like neuropathy or edema, in exception to the only toxicity recorded was neutropenia at higher dose concentrations (110 and $132 \mathrm{mg} / \mathrm{m}^{2}$ ), which was mitigated with peg-filgrastim co-administration. In conclusion, this phase I study with $41 \%$ of clinical benefit suggests $85 \mathrm{mg} / \mathrm{m}^{2}$ as a safe dose concentration for phase II clinical trial without the use of filgrastim for the effective treatment of advanced solid tumor malignancies. ${ }^{78}$

\section{Docetaxel Polymeric Micelle [Docetaxel-PM/NANOXEL-} M]

Docetaxel polymeric micelle is a nano-formulation of phyto-drug docetaxel encased with an aqueous core of polymeric micelle, with active antineoplastic effect. This nano-drug is under phase-II clinical trials for the treatment of metastatic head and neck cancer and under phase-III clinical study for bladder cancer, esophageal squamous cell carcinoma (Table 3).

\section{Docetaxel-Entrapped CriPec Nanoparticles $\left[\mathrm{CriPec}^{\circledR}\right.$ Docetaxel/CPC634]}

CPC634 is a nano-formulation of docetaxel adsorbed tuneable CriPec nanoparticles. A recent report of 2020, by Atrafi et al, demonstrated that CPC634 upon administration at $60 \mathrm{mg} / \mathrm{m}^{2}$ every 3 weeks, shows better intra-tumoral accumulation lowering toxicity like neutropenia along with skin toxicity, due to slow release of the drug compared to the conventional one. Pharmacokinetics results revealed that this nano-docetaxel formulation has seven fold lower $\mathrm{C}_{\max }$ and two fold higher half-life. It binds specifically to tubulin for inducing G2/M cell cycle phase arrest and apoptosis by reducing tumor burden in advanced solid tumor patients. ${ }^{80}$ Another recent report the author demonstrated that CPC634 nanoparticles $(75 \mathrm{mg} / \mathrm{m} 2$, for 2 cycles) increased, sustained, and prolonged intratumoral concentration of drug docetaxel by $25 \%$, lowering grade 3 and grade 4 neutropenia cases in solid tumor patients. ${ }^{81}$

\section{Docetaxel Polymeric Nanoparticle Formulation [SYP- 0709]}

This drug is a formulation of polymeric nanoparticle having docetaxel core drug (SYP-0709/Docetaxel-PNP), with enhanced anticancer activity via cell cycle arrest compared to docetaxel alone. This agent not only inhibits cancer cell growth but also restricts vascular endothelial growth factor (VEGF). A phase-I clinical trial is currently ongoing using this nano-drug in patients with advanced solid tumors to evaluate its safety, pharmacokinetics, and maximum tolerated dose (Table 3).

\section{Docetaxel-Loaded Nano-Pharmaceutical [CRLX30I]}

Docetaxel-loaded nano-pharmaceutical (CRLX301) is a tumor-targeted cyclodextrin-polyethylene glycol copolymer-conjugated nanoparticle-based formulation of docetaxel, 
with minimized systemic toxicity and better tumor accumulation. Docetaxel-loaded nano-pharmaceutical can be uptaken by tumor cells via macropinocytosis and can be used in higher doses compared to docetaxel alone with sustained-release inducing cell cycle arrest and apoptosis. Interestingly, a recent report of 2020, explained nano-docetaxel drug binds to microtubule (MT) by inducing MT-drug-target engagement (DTE). Further, increases stabilization of MT with better treatment outcome as evident from MT-DTE score of CTCs (circulating tumor cells) extracted from peripheral blood of refractory solid tumor patients. ${ }^{82}$ In a Phase $1 / 2$ a clinical trial by Ben Markman et al suggested that nano-docetaxel (CRLX301) has an enhanced antitumor activity and acceptable toxicity profile when administered up to 6 cohorts on a dose ranging from 7.5 to $75 \mathrm{mg} / \mathrm{m}^{2}$ every 3-1weeks (up to 15 cycles). Nanoformulation enabled prolonged release of drug and better tumor penetration in patients with refractory advanced solid tumor malignancy such as head and neck cancer, cholangiocarcinoma and lung etc., as compared to the conventional drug. As per FDG-PET and CT scan report, a B-RAF mutant patient observed with tumor shrinkage and partial metabolic response, and other patients were observed with the stable disease having docetaxel induced anomalies. The maximally tolerated dose was suggested as $75 \mathrm{mg} / \mathrm{m}^{2}$ for every 3 weeks of treatment. ${ }^{83}$

\section{Nanosomal Docetaxel Lipid Suspension [Doceaqualip]}

NDLS is prepared by 'Nano Aqualip Technology, for better stability, improved pharmacokinetics, and low cytotoxicity to normal tissue. The nanosized NDLS $(\sim 100 \mathrm{~nm})$ can readily pass through tumor tissue's leaky vasculature concealing it from the immune defense system. This drug has been approved in India for clinical use in breast cancer, gastric adenocarcinoma, hormone-refractory prostate cancer, and head and neck cancer patients, without any pre-medication of corticosteroids or antihistamines. ${ }^{84}$ Recently, in 2019, Ramaswamy et al reported an excellent outcome of NDLS in a pregnant woman having breast cancer metastasized to lung and liver. The patient is given with NDLS, cyclophosphamide, and doxorubicin combinatorial drug for six cycles, show effectively reducing the disease burden without significant toxicity or hypersensitivity. Further, delivering a healthy child without any adverse effect on both mother and child. ${ }^{84}$ Another clinical case reported by Radheshyam et al demonstrated herein, an adenocarcinoma patient with bone metastasis showed severe allergic reactions in treatment with docetaxel alone even after pre-treatment, with antihistamines and corticosteroids. Immediately the patient's treatment was replaced with NDLS $\left(120 \mathrm{mg} / \mathrm{m}^{2}\right)$, in combination with denosumab and filgrastim.
This NDLS formulation of docetaxel was well tolerated, without any adversity, and further continued for repeated 5 cycles. Reassessment with Ga-68 PSMA PET-CT scan reports (Figure 5) suggested improved health status having no metastases and no adversity. Furthermore, significant cancer regression has been detected with a considerable decrease in standardized uptake value (SUV) from 10.5 to 6.9 for the prostate and from 19.4 to 18.0 for skeletal lesions. ${ }^{85}$ Also, a recent case study suggests that NDLS (DoceAqualip) is strongly effective in treating stage IIIB cervical cancer, achieves complete response (RECIST 1.1 criteria) without any significant adverse effects even without any pre-hypersensitivity medication. The patient had received concomitant radiotherapy along with chemotherapy using NDLS (120$100 \mathrm{mg} / \mathrm{m}^{2}$ ) and carboplatin (AUC 6). After 2 consecutive cycles, grade II neutropenia observed, which was ameliorated by pegylated-filgrastim after every cycle of combinatorial chemotherapy. There was no evidence of residual mass inside the cervix along with no inflammed para-aortic nodes or internal iliac nodes observed after 4 cycles of treatment. Overall, after two years of follow-up, the patient did not develop any recurrence carcinoma, suggesting NDLS to be an excellent anticancer agent. $^{86}$

\section{Conclusion and Future Perspectives}

Given that cell cycle phase arrest and apoptosis play a critical role in the progression of cancer, its disruption by phytochemicals in a well-defined target specific molecular approach seems to be a promising strategy in regulating carcinogenesis. Though, so far treatments using chemically synthesized drugs have high toxic effects on the surrounding normal tissues inducing numerous severe side effects. Subsequently, alternative plant-based anticancer therapies are more effective and readily acceptable. Recent advancement in the areas of nanobiotechnology has proven to cure cancer with more potency and tissue-specific manner in conjugation with various nanoparticles and phytochemicals. Plant-based secondary metabolites such as flavonoids, phenolic compounds, alkaloids, flavanols, terpenes, steroids, flavonolignans, organo-sulfur compounds, and brassinosteroids have reported of destroying tumor cells by versatile ways, such as inducing cancer cell cycle arrest and enhancing apoptotic cell death process. Phytochemicals such as camptothecin, topotecan, irinotecan, etoposide, doxorubicin, paclitaxel, docetaxel, vinblastine, and vincristine, etc. are already in the global pharmaceutical market for various cancer treatments with superior anticancer potency. Consequently, strategic clinical trials can establish optimal anticancer 

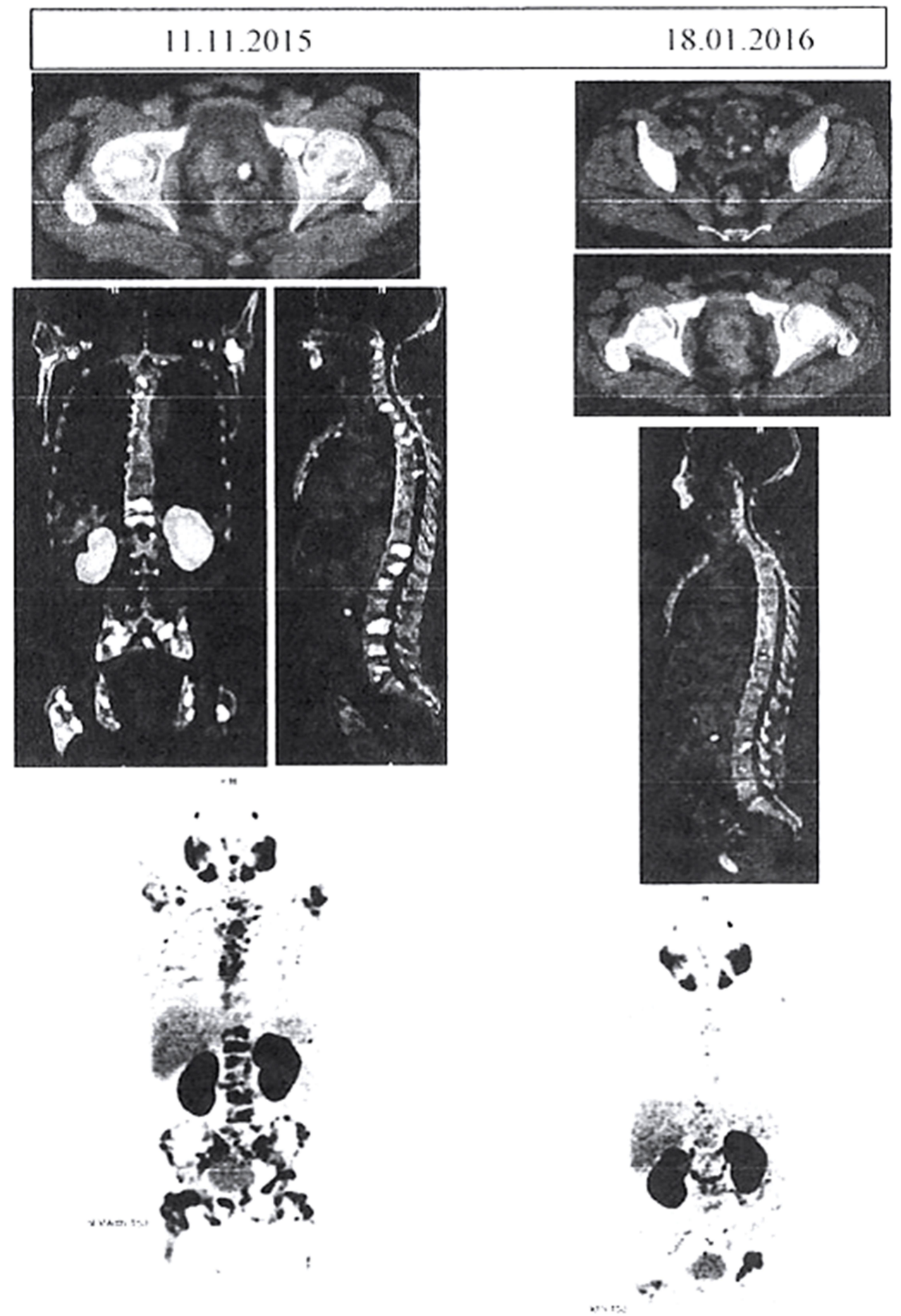

Figure 5 Comparative Ga-68 PSMA PET CT scans before and after the administration of Doceaqualip.

Notes: Left panel: Images obtained in November, 2015, showing post-TURP changes, small mild nodular hypermetabolism in the left posterior peripheral zone (likely representing residual prostatic disease) and extensive FDG-avid heterologous osteosclerotic lesions. Right panel: Images obtained in January, 2016, showing post-TURP changes, mild interval regression of the nodular hypermetabolism in the left posterior peripheral zone and morphologically stable heterogenous osteosclerotic lesions with internal regression of the metabolic activity. PSMA, prostate-specific membrane antigen; PET, positron emission tomography; CT, computed tomography; TURP, transurethral resection of the prostate; FDG, fluorodeoxyglucose. Adapted with permission from Atrafi F, Eerden R, van Hylckama Vlieg Met al Intratumoral Comparison of Nanoparticle Entrapped Docetaxel (CPC634) with Conventional Docetaxel in Patients with Solid Tumors. Clinical Cancer Research. 2020;26:clincanres.0008.2020. ${ }^{81}$ @copy right (2020), Molecular and Clinical Oncology. 
phytotherapy conditions and personalized treatment algorithms by utilizing advanced nanotechnology for the costeffective, target-specific, and less toxic chemopreventive agents to counter global demands. The current chapter provides detailed knowledge of the cancer therapeutic phytomolecules approved by the Food and Drug Administration (FDA, USA) inclusive of phytobioactives presently on the clinical trials. Inline, detailed coverage is given to the newly emerging nano-phyto-formulations (FDA-approved) of target-specific cancer theranostics via cell cycle arrest and apoptotic pathways. This chapter provides comprehensive knowledge that alludes to paving a way for the advancement of cancer research and development.

\section{Disclosure}

The authors report no conflicts of interest for this work.

\section{References}

1. Akram M, Iqbal M, Daniyal M, Khan AU. Awareness and current knowledge of breast cancer. Biol Res. 2017;50(1):33. doi:10.1186/ s40659-017-0140-9

2. Bray F, Ferlay J, Soerjomataram I, Siegel RL, Torre LA, Jemal A. Global cancer statistics 2018: GLOBOCAN estimates of incidence and mortality worldwide for 36 cancers in 185 countries. CA Cancer J Clin. 2018;68(6):394-424. doi:10.3322/caac.21492

3. Seca AML, Pinto D. Plant secondary metabolites as anticancer agents: successes in clinical trials and therapeutic application. Int $J$ Mol Sci. 2018;19(1):263. doi:10.3390/ijms19010263

4. Pistritto G, Trisciuoglio D, Ceci C, Garufi A, D’Orazi G. Apoptosis as anticancer mechanism: function and dysfunction of its modulators and targeted therapeutic strategies. Aging. 2016;8(4):603-619. doi:10.18632/aging. 100934

5. Kar S. Unraveling cell-cycle dynamics in cancer. Cell Syst. 2016;2 (1):8-10. doi:10.1016/j.cels.2016.01.007

6. Hema S, Thambiraj S, Shankaran DR. Nanoformulations for targeted drug delivery to prostate cancer: an overview. $J$ Nanosci Nanotechnol. 2018;18(8):5171-5191. doi:10.1166/jnn.2018.15420

7. Lohr M, van der Wijngaart W, Fagerberg B. [Nanoparticles for Cancer Therapy]. Lakartidningen; 2017.

8. Dhupal M, Oh JM, Tripathy DR, Kim SK, Koh SB, Park KS. Immunotoxicity of titanium dioxide nanoparticles via simultaneous induction of apoptosis and multiple toll-like receptors signaling through ROS-dependent SAPK/JNK and p38 MAPK activation. Int J Nanomedicine. 2018;13:6735-6750. doi:10.2147/ijn.s176087

9. Park K, Dhupal M, Kim CS, Park YS, Kim SK. Implication of immunokine profiling for cancer staging. Med Hypotheses. 2016;88:46-48. doi:10.1016/j.mehy.2016.01.005

10. Dhupal M, Kim C-S, Ignacio RMC, Tripathy D, Kim S-K. Effects of small black soybean product germinated with sulfur on immunoredox status in C57BL/6 mice. Mol Cell Toxicol. 2017;13(1):115124. doi:10.1007/s13273-017-0012-y

11. Vasamsetti HRRMNSDKSMK. Computational methods used in phytocompound-based drug discovery. In: Swamy MK, editor. PlantDerived Bioactives. Singapore: Springer; 2020.

12. Natesan MVTDRRMMKVKS. Pelargonidin, a dietary anthocyanidin in the prevention of colorectal cancer and its chemoprotective mechanisms. In: Natesan MVTDRRMMKVKS, editor. PlantDerived Bioactives. Singapore: Springer; 2020:119-135.
13. Madhusmita Dhupal MKG, Tripathy DR, Kumar M, Yi DK, Nanda SS, Chowdhury D. Recent advances in pharmaceutical applications of natural carbohydrate polymer gum tragacanth. In: Amit Kumar Nayak MSH, Pal D, editors. Natural Polymers for Pharmaceutical Applications. USA: Apple Academic Press, Incorporated; 2019:1927-1951.

14. Lee KW, Ching SM, Hoo FK, Ramachandran V, Swamy MK. Traditional medicinal plants and their therapeutic potential against major cancer types. In: Akhtar MS, Swamy MK, editors. Anticancer Plants: Natural Products and Biotechnological Implements. Vol. 2. Singapore: Springer Singapore; 2018:383-410.

15. Zeidner JF, Foster MC, Blackford AL, et al. Final results of a randomized multicenter phase II study of alvocidib, cytarabine, and mitoxantrone versus cytarabine and daunorubicin $(7+3)$ in newly diagnosed high-risk acute myeloid leukemia (AML). Leuk Res. 2018;72:92-95. doi:10.1016/j.leukres.2018.08.005

16. Topotecan. Drugs and Lactation Database (Lactmed). Bethesda (MD): National Library of Medicine (US); 2006.

17. Oh IJ, Kim KS, Park CK, et al. Belotecan/cisplatin versus etoposide/ cisplatin in previously untreated patients with extensive-stage small cell lung carcinoma: a multi-center randomized phase III trial. $B M C$ Cancer. 2016;16:690. doi:10.1186/s12885-016-2741-z

18. Fujita K, Kubota Y, Ishida H, Sasaki Y. Irinotecan, a key chemotherapeutic drug for metastatic colorectal cancer. World J Gastroenterol. 2015;21(43):12234-12248. doi:10.3748/wjg.v21.i43.12234

19. Liu X, Adane E, Tang F, Leggas M. Pharmacokinetic modeling of the blood-stable camptothecin analog AR-67 in two different formulations. Biopharm Drug Dispos. 2019;40(8):265-275. doi:10.1002/bdd.2199

20. Arnold SM, Rinehart JJ, Tsakalozou E, et al. A phase I study of 7-tbutyldimethylsilyl-10-hydroxycamptothecin in adult patients with refractory or metastatic solid malignancies. Clin Cancer Res. 2010;16(2):673-680. doi:10.1158/1078-0432.CCR-09-2429

21. Chatterjee A, Digumarti R, Mamidi RN, et al. Safety, tolerability, pharmacokinetics, and pharmacodynamics of an orally active novel camptothecin analog, DRF-1042, in refractory cancer patients in a phase I dose escalation study. J Clin Pharmacol. 2004;44(7):723736. doi:10.1177/0091270004265647

22. Shah NN, Merchant MS, Cole DE, et al. Vincristine sulfate liposomes injection (VSLI, Marqibo(R)): results from a phase I study in children, adolescents, and young adults with refractory solid tumors or leukemias. Pediatr Blood Cancer. 2016;63(6):997-1005. doi: $10.1002 /$ pbc. 25937

23. Wouda RM, Miller ME, Chon E, Stein TJ. Clinical effects of vinorelbine administration in the management of various malignant tumor types in dogs: 58 cases (1997-2012). J Am Vet Med Assoc. 2015;246 (11):1230-1237. doi:10.2460/javma.246.11.1230

24. Kulke MH, Muzikansky A, Clark J, et al. A Phase II trial of vinorelbine in patients with advanced gastroesophageal adenocarcinoma. Cancer Invest. 2006;24(4):346-350. doi:10.1080/07357900600705268

25. Gezici S, Sekeroglu N. Current perspectives in the application of medicinal plants against cancer: novel therapeutic agents. Anticancer Agents Med Chem. 2019;19(1):101-111. doi:10.2174/ 1871520619666181224121004

26. Bellmunt J, Théodore C, Demkov T, et al. Phase III trial of vinflunine plus best supportive care compared with best supportive care alone after a platinum-containing regimen in patients with advanced transitional cell carcinoma of the urothelial tract. J Clin Oncol. 2009;27 (27):4454-4461. doi:10.1200/jco.2008.20.5534

27. Garon EB, Neidhart JD, Gabrail NY, de Oliveira MR, Balkissoon J, Kabbinavar F. A randomized Phase II trial of the tumor vascular disrupting agent CA4P (fosbretabulin tromethamine) with carboplatin, paclitaxel, and bevacizumab in advanced nonsquamous non-small-cell lung cancer. Onco Targets Ther. 2016;9:7275-7283. doi:10.2147/ott.s109186

28. Bahleda R, Sessa C, Del Conte G, et al. Phase I clinical and pharmacokinetic study of ombrabulin (AVE8062) combined with cisplatin/docetaxel or carboplatin/paclitaxel in patients with advanced solid tumors. Invest New Drugs. 2014;32(6):1188-1196. doi:10.1007/s10637-014-0119-0 
29. Isono M, Sato A, Asano T, Okubo K, Asano T. Evaluation of therapeutic potential of phenoxodiol, a novel isoflavone analog, in renal cancer cells. Anticancer Res. 2018;38(10):5709-5716. doi:10.21873/anticanres. 12908

30. Howes JB, de Souza PL, West L, Huang LJ, Howes LG. Pharmacokinetics of phenoxodiol, a novel isoflavone, following intravenous administration to patients with advanced cancer. $B M C$ Clin Pharmacol. 2011;11:1. doi:10.1186/1472-6904-11-1

31. Choueiri TK, Mekhail T, Hutson TE, Ganapathi R, Kelly GE, Bukowski RM. Phase I trial of phenoxodiol delivered by continuous intravenous infusion in patients with solid cancer. Ann Oncol. 2006;17(5):860-865. doi:10.1093/annonc/mdl010

32. Mukund V, Mukund D, Sharma V, Mannarapu M, Alam A. Genistein: its role in metabolic diseases and cancer. Crit Rev Oncol Hematol. 2017;119:13-22. doi:10.1016/j.critrevonc.2017.09.004

33. Kostovic K, Gulin SJ, Mokos ZB, Ceovic R. Topical ingenol mebutate: a new treatment modality for multiple actinic keratoses and field cancerization. Anticancer Agents Med Chem. 2017;17(10):13041311. doi:10.2174/1871520617666170213130523

34. Rios JL, Manez S. New pharmacological opportunities for betulinic acid. Planta Med. 2018;84(1):8-19. doi:10.1055/s-0043-123472

35. Wong DJL, Hurvitz SA. Recent advances in the development of antiHER2 antibodies and antibody-drug conjugates. Ann Transl Med. 2014;2(12).

36. Fimognari C, Hrelia P. Sulforaphane as a promising molecule for fighting cancer. Mutat Res. 2007;635(2-3):90-104. doi:10.1016/j. mrrev.2006.10.004

37. Granja A, Pinheiro M, Reis S. Epigallocatechin gallate nanodelivery systems for cancer therapy. Nutrients. 2016;8(5):307. doi:10.3390/ nu8050307

38. Devassy JG, Nwachukwu ID, Jones PJ. Curcumin and cancer: barriers to obtaining a health claim. Nutr Rev. 2015;73(3):155-165. doi:10.1093/nutrit/nuu064

39. Swiecicki PL, Bellile E, Sacco AG, et al. A phase II trial of the BCL-2 homolog domain 3 mimetic AT-101 in combination with docetaxel for recurrent, locally advanced, or metastatic head and neck cancer. Invest New Drugs. 2016;34(4):481-489. doi:10.1007/s10637-016-0364-5

40. Yang Y, Zhou X, Xu M, et al. beta-lapachone suppresses tumour progression by inhibiting epithelial-to-mesenchymal transition in NQO1-positive breast cancers. Sci Rep. 2017;7(1):2681. doi:10.1038/s41598-017-02937-0

41. D'Agostino G, Del Campo J, Mellado B, et al. A multicenter phase II study of the cryptophycin analog LY355703 in patients with platinum-resistant ovarian cancer. Int J Gynecol Cancer. 2006;16(1):7176. doi:10.1111/j.1525-1438.2006.00276.x

42. Edelman MJ, Gandara DR, Hausner P, et al. Phase 2 study of cryptophycin 52 (LY355703) in patients previously treated with platinum based chemotherapy for advanced non-small cell lung cancer. Lung Cancer (Amsterdam, Netherlands). 2003;39(2):197-199. doi:10.1016/s0169-5002(02)00511-1

43. Qi F, Zhao L, Zhou A, et al. The advantages of using traditional Chinese medicine as an adjunctive therapy in the whole course of cancer treatment instead of only terminal stage of cancer. Biosci Trends. 2015;9(1):16-34. doi:10.5582/bst.2015.01019

44. Higgins MJ, Prowell TM, Blackford AL, et al. A short-term biomarker modulation study of simvastatin in women at increased risk of a new breast cancer. Breast Cancer Res Treat. 2012;131(3):915-924. doi:10.1007/s10549-011-1858-7

45. Armstrong DK, Bundy B, Wenzel L, et al. Intraperitoneal cisplatin and paclitaxel in ovarian cancer. $N$ Engl $J$ Med. 2006;354(1):34-43. doi:10.1056/NEJMoa052985

46. Payne M, Ellis P, Dunlop D, et al. DHA-paclitaxel (Taxoprexin) as first-line treatment in patients with stage IIIB or IV non-small cell lung cancer: report of a phase II open-label multicenter trial. $J$ Thorac Oncol. 2006;1(9):984-990. doi:10.1016/S1556-0864(15)31631-2
47. Robert F, Harper K, Ackerman J, Gupta S. A phase I study of larotaxel (XRP9881) administered in combination with carboplatin in chemotherapy-naive patients with stage IIIB or stage IV non-small cell lung cancer. Cancer Chemother Pharmacol. 2010;65(2):227234. doi:10.1007/s00280-009-1026-5

48. Silvani A, De Simone I, Fregoni V, et al. Multicenter, single arm, phase II trial on the efficacy of ortataxel in recurrent glioblastoma. $J$ Neurooncol. 2019;142(3):455-462. doi:10.1007/s11060-019-03116-z

49. Ramanathan RK, Picus J, Raftopoulos H, et al. A phase II study of milataxel: a novel taxane analogue in previously treated patients with advanced colorectal cancer. Cancer Chemother Pharmacol. 2008;61 (3):453-458. doi:10.1007/s00280-007-0489-5

50. McQuade JL, Posada LP, Lecagoonporn S, et al. A phase I study of TPI 287 in combination with temozolomide for patients with metastatic melanoma. Melanoma Res. 2016;26(6):604-608. doi:10.1097/ cmr.0000000000000296

51. Mitchell D, Bergendahl G, Ferguson W, et al. A phase 1 trial of TPI 287 as a single agent and in combination with temozolomide in patients with refractory or recurrent neuroblastoma or medulloblastoma. Pediatr Blood Cancer. 2016;63(1):39-46. doi:10.1002/ pbc. 25687

52. Saif MW, Sarantopoulos J, Patnaik A, Tolcher AW, Takimoto C, Beeram M. Tesetaxel, a new oral taxane, in combination with capecitabine: a Phase I, dose-escalation study in patients with advanced solid tumors. Cancer Chemother Pharmacol. 2011;68(6):1565-1573. doi:10.1007/s00280-011-1639-3

53. Oudard S. TROPIC: phase III trial of cabazitaxel for the treatment of metastatic castration-resistant prostate cancer. Future Oncol (London, England). 2011;7(4):497-506. doi:10.2217/fon.11.23

54. Rouesse J, Spielmann M, Turpin F, Le Chevalier T, Azab M, Mondesir JM. Phase II study of elliptinium acetate salvage treatment of advanced breast cancer. Eur J Cancer. 1993;29(6):856-859. doi:10.1016/s0959-8049(05)80424-1

55. Rosshandler Y, Shen AQ, Cortes J, Khoury HJ. Omacetaxine mepesuccinate for chronic myeloid leukemia. Expert Rev Hematol. 2016;9 (5):419-424. doi:10.1586/17474086.2016.1151351

56. Rafique R, Gul AR, Lee IG, et al. Photo-induced reactions for disassembling of coloaded photosensitizer and drug molecules from upconversion-mesoporous silica nanoparticles: an effective synergistic cancer therapy. Mater Sci Eng C. 2020;110:110545. doi:10.1016/j. msec.2019.110545

57. Ashrafizadeh M, Mohammadinejad R, Kailasa SK, Ahmadi Z, Afshar EG, Pardakhty A. Carbon dots as versatile nanoarchitectures for the treatment of neurological disorders and their theranostic applications: a review. Adv Colloid Interface Sci. 2020;278:102123. doi:10.1016/j. cis. 2020.102123

58. Rafique R, Kailasa SK, Park TJ. Recent advances of upconversion nanoparticles in theranostics and bioimaging applications. Trends Anal Chem. 2019;120:115646. doi:10.1016/j.trac.2019.115646

59. Phan LMT, Gul AR, Le TN, et al. One-pot synthesis of carbon dots with intrinsic folic acid for synergistic imaging-guided photothermal therapy of prostate cancer cells. Biomater Sci. 2019;7(12):51875196. doi:10.1039/C9BM01228A

60. Gradishar WJ, Tjulandin S, Davidson N, et al. Phase III trial of nanoparticle albumin-bound paclitaxel compared with polyethylated castor oil-based paclitaxel in women with breast cancer. J Clin Oncol. 2005;23(31):7794-7803. doi:10.1200/jco.2005.04.937

61. Gradishar WJ, Krasnojon D, Cheporov S, et al. Phase II trial of nabpaclitaxel compared with docetaxel as first-line chemotherapy in patients with metastatic breast cancer: final analysis of overall survival. Clin Breast Cancer. 2012;12(5):313-321. doi:10.1016/j. clbc.2012.05.001

62. Von Hoff DD, Ervin T, Arena FP, et al. Increased survival in pancreatic cancer with nab-paclitaxel plus gemcitabine. $N$ Engl $J$ Med. 2013;369(18):1691-1703. doi:10.1056/NEJMoa1304369 
63. Petrillo A, Pappalardo A, Calabrese F, et al. First line nab-paclitaxel plus gemcitabine in elderly metastatic pancreatic patients: a good choice beyond age. J Gastrointest Oncol. 2019;10(5):910-917. doi:10.21037/jgo.2019.06.02

64. Asahina H, Oizumi S, Takamura K, et al. A prospective phase II study of carboplatin and nab-paclitaxel in patients with advanced non-small cell lung cancer and concomitant interstitial lung disease (HOT1302). Lung Cancer (Amsterdam, Netherlands). 2019;138:6571. doi:10.1016/j.lungcan.2019.09.020

65. Xu X, Wang L, Xu HQ, Huang XE, Qian YD, Xiang J. Clinical comparison between paclitaxel liposome (Lipusu(R)) and paclitaxel for treatment of patients with metastatic gastric cancer. Asian Pacif J Cancer Prev. 2013;14(4):2591-2594. doi:10.7314/ apjcp.2013.14.4.2591

66. Lee S-W, Kim Y-M, Cho $\mathrm{CH}$, et al. An open-label, randomized, parallel, phase II trial to evaluate the efficacy and safety of a cremophor-free polymeric micelle formulation of paclitaxel as first-line treatment for ovarian cancer: a Korean Gynecologic Oncology Group Study (KGOG-3021). Cancer Res Treat. 2018;50(1):195203. doi: $10.4143 / \mathrm{crt} .2016 .376$

67. Park IH, Sohn JH, Kim SB, et al. An open-label, randomized, parallel, phase III trial evaluating the efficacy and safety of polymeric micelle-formulated paclitaxel compared to conventional cremophor EL-based paclitaxel for recurrent or metastatic HER2-negative breast cancer. Cancer Res Treat. 2017;49(3):569-577. doi:10.4143/ crt.2016.289

68. Fujiwara Y, Mukai H, Saeki T, et al. A multi-national, randomised, openlabel, parallel, phase III non-inferiority study comparing NK105 and paclitaxel in metastatic or recurrent breast cancer patients. Br J Cancer 2019;120(5):475-480. doi:10.1038/s41416-019-0391-z

69. Wang-Gillam A, Hubner RA, Siveke JT, et al. NAPOLI-1 Phase 3 study of liposomal irinotecan in metastatic pancreatic cancer: final overall survival analysis and characteristics of long-term survivors. Eur J Cancer. 2019;108:78-87. doi:10.1016/j.ejca.2018.12.007

70. Yang SH, Lin CC, Lin ZZ, Tseng YL, Hong RL. A phase I and pharmacokinetic study of liposomal vinorelbine in patients with advanced solid tumor. Invest New Drugs. 2012;30(1):282-289. doi:10.1007/s10637-010-9522-3

71. Douer D. Efficacy and safety of vincristine sulfate liposome injection in the treatment of adult acute lymphocytic leukemia. Oncologist. 2016;21(7):840-847. doi:10.1634/theoncologist.2015-0391

72. Verschraegen CF, Gilbert BE, Loyer E, et al. Clinical evaluation of the delivery and safety of aerosolized liposomal 9-nitro-20(s)-camptothecin in patients with advanced pulmonary malignancies. Clin Cancer Res. 2004;10(7):2319-2326. doi:10.1158/1078-0432.ccr0929-3

73. Eliasof S, Lazarus D, Peters CG, et al. Correlating preclinical animal studies and human clinical trials of a multifunctional, polymeric nanoparticle. Proc Natl Acad Sci. 2013;110(37):15127-15132. doi:10.1073/pnas. 1309566110

74. Sanoff HK, Moon DH, Moore DT, et al. Phase I/II trial of nano-camptothecin CRLX101 with capecitabine and radiotherapy as neoadjuvant treatment for locally advanced rectal cancer. Nanomed Nanotechnol Biol Med. 2019;18:189-195. doi:10.1016/j.nano.2019.02.021

International Journal of Nanomedicine

\section{Publish your work in this journal}

The International Journal of Nanomedicine is an international, peerreviewed journal focusing on the application of nanotechnology in diagnostics, therapeutics, and drug delivery systems throughout the biomedical field. This journal is indexed on PubMed Central, MedLine, CAS, SciSearch ${ }^{\mathbb{R}}$, Current Contents ${ }^{\mathbb{B}} /$ Clinical Medicine, $^{2}$
75. Chao J, Lin J, Frankel P, et al. Pilot trial of CRLX101 in patients with advanced, chemotherapy-refractory gastroesophageal cancer. $J$ Gastrointest Oncol. 2017;8(6):962-969. doi:10.21037/ jgo.2017.08.10

76. Bolger GT, Licollari A, Tan A, et al. Pharmacokinetics of liposomal curcumin (Lipocurc ${ }^{\mathrm{TM}}$ ) infusion: effect of co-medication in cancer patients and comparison with healthy individuals. Cancer Chemother Pharmacol. 2019;83(2):265-275. doi:10.1007/s00280-018-3730-5

77. Greil R, Greil-Ressler S, Weiss L, et al. A phase 1 dose-escalation study on the safety, tolerability and activity of liposomal curcumin (Lipocurc ${ }^{\mathrm{TM}}$ ) in patients with locally advanced or metastatic cancer. Cancer Chemother Pharmacol. 2018;82(4):695-706. doi:10.1007/ s00280-018-3654-0

78. Deeken JF, Slack R, Weiss GJ, et al. A phase I study of liposomalencapsulated docetaxel (LE-DT) in patients with advanced solid tumor malignancies. Cancer Chemother Pharmacol. 2013;71 (3):627-633. doi:10.1007/s00280-012-2048-y

79. Mahalingam D, Nemunaitis JJ, Malik L, et al. Phase I study of intravenously administered ATI-1123, a liposomal docetaxel formulation in patients with advanced solid tumors. Cancer Chemother Pharmacol. 2014;74(6):1241-1250. doi:10.1007/ s00280-014-2602-x

80. Atrafi F, Dumez H, Mathijssen R, et al. A phase I dose-escalation and pharmacokinetic study of a micellar nanoparticle with entrapped docetaxel (CPC634) in patients with advanced solid tumours. J Control Release. 2020;325:191-197. doi:10.1016/j. jconrel.2020.06.020

81. Atrafi F, Eerden R, van Hylckama Vlieg M, et al. Intratumoral comparison of nanoparticle entrapped docetaxel (CPC634) with conventional docetaxel in patients with solid tumors. Clin Cancer Res. 2020;26:3537-3545. doi:10.1158/1078-0432.CCR-20-0008

82. Mukhtar E, Worroll D, Galletti G, et al. Quantitative analysis of taxane drug target engagement of microtubules in circulating tumor cells from metastatic castration resistant prostate cancer patients treated with CRXL301, a nanoparticle of docetaxel. Cancer Drug Resist. 2020;3:60-70. doi:10.20517/cdr.2019.116

83. Markman B, De Souza PL, Dees EC, et al. A phase 1 study of CRLX301, a novel nanoparticle-drug conjugate (NDC) containing docetaxel (DOC), in patients with refractory solid tumors. $J$ Clin Oncol. 2016;34(15_suppl):2526. doi:10.1200/ JCO.2016.34.15 suppl.2526

84. Ramaswamy R, Joshi N, Khan MA, Siddhara S. Nanosomal docetaxel lipid suspension based chemotherapy in a pregnant $\mathrm{MBC}$ patient - a case report. Onco Targets Ther. 2019;12:5679-5685. doi:10.2147/OTT.S206573

85. Naik R, Khan MA. Doceaqualip in a patient with prostate cancer who had an allergic reaction to conventional docetaxel: a case report. Mol Clin Oncol. 2017;6(3):341-343. doi:10.3892/mco.2017.1147

86. Prasanna R, Bunger D, Khan MA. Efficacy and safety of DoceAqualip in a patient with locally advanced cervical cancer: a case report. Mol Clin Oncol. 2018;8(2):296-299. doi:10.3892/ mco.2017.1519

Journal Citation Reports/Science Edition, EMBase, Scopus and the Elsevier Bibliographic databases. The manuscript management system is completely online and includes a very quick and fair peer-review system, which is all easy to use. Visit http://www.dovepress.com/ testimonials.php to read real quotes from published authors. 